\title{
Hygroscopic properties of the ambient aerosol in southern Sweden - a two year study
}

\author{
E. O. Fors, E. Swietlicki, B. Svenningsson, A. Kristensson, G. P. Frank, and M. Sporre \\ Lund University, Department of Physics, Division of Nuclear Physics, Lund, Sweden
}

Received: 31 January 2011 - Published in Atmos. Chem. Phys. Discuss.: 23 February 2011

Revised: 1 August 2011 - Accepted: 4 August 2011 - Published: 16 August 2011

\begin{abstract}
The hygroscopic growth of the atmospheric aerosol is a critical parameter for quantifying the anthropogenic radiative forcing. Until now, there has been a lack of long term measurements due to limitations in instrumental techniques. In this work, for the first time the seasonal variation of the hygroscopic properties of a continental background aerosol has been described, based on more than two years of continuous measurements. In addition to this, the diurnal variation of the hygroscopic growth has been investigated, as well as the seasonal variation in $\mathrm{CCN}$ concentration. These physical properties of the aerosol have been measured with a Hygroscopic Tandem Differential Mobility Analyzer (H-TDMA), a Differential Mobility Particle Sizer (DMPS), and a Cloud Condensation Nuclei Counter (CCNC). The results show that smaller particles are generally less hygroscopic than larger ones, and that there is a clear difference in the hygroscopic properties between the Aitken and the accumulation mode. A seasonal cycle was found for all particle sizes. In general, the average hygroscopic growth is lower during wintertime, due to an increase in the relative abundance of less hygroscopic or barely hygroscopic particles. Monthly averages showed that the hygroscopic growth factors of the two dominating hygroscopic modes (one barely hygroscopic and one more hygroscopic) were relatively stable. The hygroscopic growth additionally showed a diurnal cycle, with higher growth factors during day time. CCN predictions based on H-TDMA data underpredicted the activated $\mathrm{CCN}$ number concentration with $7 \%$ for a $1 \%$ water supersaturation ratio. The underprediction increases with decreasing $s$, most likely due to a combination of measurement and modeling uncertainties. It was found that although the aerosol is often externally mixed, recalcu-
\end{abstract}

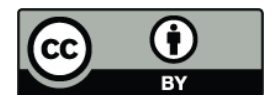

Correspondence to: E. O. Fors (erik.fors@nuclear.lu.se) lating to an internal mixture with respect to hygroscopicity did not change the $\mathrm{CCN}$ concentration as a function of supersaturation significantly.

\section{Introduction}

The hygroscopic properties of atmospheric aerosols are of utmost importance for the climate. As aerosol particles move around the atmosphere, they continuously interact with the surrounding water vapour, changing in size with the relative humidity (RH). As the light scattering properties of particles are highly dependent on particle size, the hygroscopicity of the aerosol at subsaturated conditions will have great implications for the light scattering of the atmosphere (FierzSchmidhauser et al., 2010; McFiggans et al., 2006). The light scattering and light absorption of the aerosol is commonly called "the direct aerosol climate effect" and is believed to cool the atmosphere, an effect that is enhanced by anthropogenic emissions (Solomon et al., 2007).

The particle-water vapour interaction also plays a vital role in cloud formation, as the particles provide a surface on which to condense when the air is saturated with water. At a water vapour saturation ratio just above $100 \%$, the particles leave the equilibrium domain and start to grow unrestrained as long as water vapour is available for condensation. The particles are said to activate into cloud droplets, often growing from $100 \mathrm{~nm}$ to $10 \mu \mathrm{m}$ in a few hours. The number of activated particles in a cloud is highly dependent on the hygroscopic properties of the particles (McFiggans et al., 2006) as well as the size distribution of the aerosol (Dusek et al., 2006) which determines how many activated cloud droplets will form for a given supersaturation $(s)$ ratio. This in turn affects both the reflective properties and precipitation pattern of the cloud (Rosenfeld, 1999, 2000), effects which also are

Published by Copernicus Publications on behalf of the European Geosciences Union. 
believed to exert a cooling of the atmosphere, and which are known as the first and second aerosol indirect effects.

To quantify the water uptake at subsaturated conditions, the concept of hygroscopic diameter growth factor (GF) is commonly used where the GF is defined according to

$\mathrm{GF}=\frac{D_{\mathrm{w}}}{D_{\mathrm{p}}}$

where $D_{\mathrm{w}}$ is the wet particle diameter at a given $\mathrm{RH}$ and $D_{\mathrm{p}}$ is the dry diameter of the particle. At subsaturated conditions $(\mathrm{RH}<100 \%)$, particles rapidly reach equilibrium with the surrounding atmosphere, with GFs ranging between 1 and $\sim 2.1$ at $90 \% \mathrm{RH}$, where 1 represents completely nonhygroscopic particles, such as fresh soot, and $\sim 2.1$ represents sea salt particles (Swietlicki et al., 2008).

Hygroscopic measurements of atmospheric aerosol particles have been carried out for many years, with Sekigawa (1983) and Rader and McMurry (1986) doing pioneering work in using the measurement principle of two DMAs in series with a humidification conditioning unit in between on an atmospheric aerosol. This setup is commonly known as the Hygroscopic Tandem Differential Mobility Analyzer (H-TDMA). Since the first measurements, there have been a multitude of measurement campaigns using H-TDMAs in various environments all over the globe. Results from these measurements show that the hygroscopicity of a particle is highly dependent on the source and physicochemical age of the particle.

The hygroscopic growth can be subdivided into different classes with respect hygroscopicity. One classification is based on diameter growth factor at $90 \% \mathrm{RH}$ with respect to ammonium sulphate. For $100 \mathrm{~nm}$ dry particles diameter these boundaries are: Barely hygroscopic $(\mathrm{BH} ; \mathrm{GF}=1.0-1.11)$, Less Hygroscopic (LH; GF =1.11-1.33), More Hygroscopic $(\mathrm{MH} ; \mathrm{GF}=1.33-1.85)$ and Sea Salt $(\mathrm{GF}>1.85)$ (Swietlicki et al., 2008). Often the ambient aerosol is externally mixed, meaning that for any given size, there are particles present in two or more of the hygroscopic classes, with different GFs dependent on air mass origin and different chemical age. However, the degree of external mixture is dependent both on location and on size.

In previous H-TDMA measurements, the occurrence of external mixtures varies a lot between different measurement campaigns. The aerosol tends to be less externally mixed for Aitken mode particles than for accumulation mode particles (Swietlicki et al., 2008). This might be explained by the fact that some of the larger particles have been cloud processed, during which they absorbed soluble gases such as $\mathrm{SO}_{2}, \mathrm{H}_{2} \mathrm{SO}_{4}, \mathrm{HNO}_{3}$ or $\mathrm{NH}_{3}$. When the particles dry out, soluble ions tend to stay in the particle phase, increasing its solubility.

On the other hand, also the smaller particles are often externally mixed. This is most likely due to a combination of different sources and different age. Small particles tend to consist of different kinds of organic substances, both from primary (meaning emissions of particles at the emission source) and secondary (meaning that the particle mass originates from condensation) sources. Fresh emissions from e.g. diesel car exhaust contain a combination of non-hygroscopic Hydrocarbon-like Organic Aerosol (HOA) in the particle phase, gas phase Volatile Organic Compounds (VOCs) and a myriad of combinations in between with different vapour pressures. As the different VOCs are oxidised in the atmosphere, the molecules tend to grow, due to an increasing number of functional groups. This chemical ageing is also linked to volatility, and as the vapour pressure decreases, the organic vapours are driven towards the particle phase. As the photochemistry continues to oxidise the organics, the $\mathrm{O}: \mathrm{C}$ ratio in the organic aerosol (OA) increases, which in turn also increases the hygroscopicity of the OA (Jimenez et al., 2009).

To estimate how many particles in a given aerosol will activate into cloud droplets at a certain supersaturation ratio $(s)$, it is possible to use H-TDMA measurements in combination with size distribution measurements. Unfortunately, $\mathrm{H}$ TDMA measurements of aerosol particles have until recently been limited to short field campaigns of maximum a few months in duration, since these instruments typically require frequent attention, and have therefore not been suitable for unattended long-term operation. An alternate way to measure $\mathrm{CCN}$ concentration is using a $\mathrm{CCN}$ counter (CCNC). Besides being easier to handle, CCNCs have the advantage of a direct measurement - no modelling or combining of different measurement techniques are necessary. However, when operated as in this study, they do not give any information about the degree of external mixture of the aerosol, something that is essential for a deeper understanding of the atmospheric processes that governs the number of $\mathrm{CCN}$. The $\mathrm{H}-$ TDMA, though somewhat more complicated, provides this link between the atmospheric aerosol size distribution and the number of activated CCN for a given $s$.

During the last years several H-TDMAs have been designed for long term measurements within the European Supersites for Atmospheric Aerosol Research (EUSAAR) project (www.eusaar.net) (Duplissy et al., 2009; Nilsson et al., 2009) and Kammermann et al. (2010a) were the first ones to describe a full year of H-TDMA data. Even though diurnal cycles were observed, no clear seasonal trend could be observed over a 13 month measurement period in the Swiss free troposphere.

In this work, more than two years of H-TDMA, size distribution and CCNC data are presented, for the first time revealing the annual cycle of the hygroscopic properties at subsaturated conditions as well as the $\mathrm{CCN}$ concentrations of a European background aerosol. The aims of this work were

1. To characterize the hygroscopic properties of the aerosol at the EMEP/EUSAAR field station Vavihill $\left(56^{\circ} 01^{\prime} \mathrm{N}, 13^{\circ} 09^{\prime} \mathrm{E}, 172 \mathrm{~m}\right.$ a.s.1.), which is situated in a rural environment in the southern part of Sweden 
(Kristensson et al., 2008), including the diurnal and seasonal variation of the hygroscopic growth.

2. To quantify how well we are able to predict CCN concentrations using size distribution and H-TDMA data.

3. To derive seasonal CCN concentration functions as dependent on supersaturation for all four seasons.

\section{Methods}

The measurements included in this work were carried out the measurement station Vavihill. The aerosol was sampled through a PM10 inlet, excluding all particles with an aerodynamic diameter larger than $10 \mu \mathrm{m}$. The temperature inside the measurement station was kept constant with air conditioning at $21 \pm 2{ }^{\circ} \mathrm{C}$.

\subsection{H-TDMA}

The hygroscopic properties at subsaturated conditions were measured with an H-TDMA constructed at Lund University which was specifically constructed for long term measurements, in accordance with the design and operation criteria decided within the EU FP6 Infrastructure Project EUSAAR. The aerosol was dried with a nafion drier and charged with an ${ }^{85} \mathrm{Kr}$ diffusion charger before it entered the first DMA (DMA1), a Vienna type, $28 \mathrm{~cm}$ long, which was housed in an insulated box at a well defined temperature, typically $20^{\circ} \mathrm{C}$. The RH before DMA1 was always lower than $30 \%$. The residence time between the nafion drier and DMA1 was approximately $1 \mathrm{~s}$. In DMA1 a fixed voltage was applied, corresponding to a certain dry size, or more precisely to a certain electrical mobility. After DMA1, the aerosol was quasimonodisperse, meaning that it had a mobility distribution corresponding to the transfer function of DMA1. The flow ratio between the aerosol and the sheath flow was set to 1:10, to minimize broadening of the spectrum.

After DMA1, the aerosol passed through Gore-Tex tubing, with temperature controlled water flowing on the outside of the membrane in opposite direction. The water migration through the membrane was controlled by the temperature of the water. After this conditioning unit, the aerosol flowed into a second housing, with a temperature $2 \mathrm{~K}$ lower than the first. Since the saturation vapor pressure of the water decreases with temperature, the RH increased before it entered the second DMA (DMA2) and the use of a closed loop for the sheath and excess flow made the RH inside DMA2 asymptotically approach the $\mathrm{RH}$ of the aerosol entering the DMA.

By ensuring a well controlled temperature at $20^{\circ} \mathrm{C}$, the DMA2 RH was kept at $90 \pm 0.1 \%$. The residence time after the humidifier was $\sim 1 \mathrm{~s}$, after which the voltage in DMA2 was continuously scanned over sizes corresponding to diameter growth factors of $0.85-3.0$, to ensure that no particles were missed. The particles were detected downstream
DMA2 using a Condensation Particle Counter (CPC) (TSI model 3760A). In this case the dry sizes were selected cyclically to $35,50,75,110,165$ and $265 \mathrm{~nm}$, with two scans of 300 s per size (one up- and one down scan), making the time resolution of the measurements roughly one hour.

To validate the measurements, automatic $\left(\mathrm{NH}_{4}\right)_{2} \mathrm{SO}_{4}$ scans were carried out on a daily basis, as required by EUSAAR standards. These measurements consisted of one cycle, meaning that roughly $4 \%$ of the data consisted of salt scans. Dry scans were carried out on an irregular basis, with about 2-3 month intervals, and dry sizes were found stable within $2 \%$ of the nominal dry sizes. For further details regarding the H-TDMA system, see Nilsson et al. (2009).

H-TDMA measurements started May 2008 and this paper covers the first 27 months of operation, ending in July 2010. During this time data coverage varied from month to month with an average of $66 \%$, corresponding to roughly 200000 scans. To facilitate the inversion, the TDMAinv software was used and continuous GF Probability Density Functions (GF-PDFs) were extracted from the data (Gysel et al., 2009). Criteria for a scan to be considered for inversion were that the average DMA2 RH in the scan should be between 88 and $92 \%$, that the total number of counted particles should be more than 20, that DMA1 RH should be lower than $20 \%$ (to avoid an underestimated growth factor) and that the $\left(\mathrm{NH}_{4}\right)_{2} \mathrm{SO}_{4}$ scans confirmed the system functionality by a growth factor that was within corresponding values of $\pm 1.2 \% \mathrm{RH}$ of what can be expected according to growth factors predicted by the data from Tang and Munkelwitz (1994) and Potukuchi and Wexler (1995). To increase the comparability between different scans, the GF-PDFs were recalculated to $90 \%$ in TDMAinv, using the $\kappa$ model described in section 2.4 (Gysel et al., 2009).

\subsection{DMPS}

To measure the particle size distribution, a Differential Mobility Particle Sizer (DMPS) was used. The DMPS was constructed at Lund University and is a so called 'twin-DMPS', meaning that two parallel DMAs were used. The aerosol flow was dried and charged with an ${ }^{85} \mathrm{Kr}$ diffusion charger, whereafter the flow was split into two parts. One part of the flow was directed towards a Vienna-type nano DMA measuring diameters from 3.4 to $21.5 \mathrm{~nm}$ with a flow ratio of $3: 21$ and the other part to a Vienna type long DMA, measuring between 21.5 and $857 \mathrm{~nm}$ with a flow ratio of 0.9:6.5.

By measuring the $21.5 \mathrm{~nm}$ concentration with both DMAs, an internal check was included in the measurements, as the two parallel systems should produce the same concentration, taking into account flows, CPC calibration curves and diffusion losses. The particles selected in the nano DMA and the long DMA were counted using two CPCs (TSI models 7610 and 3025 , respectively). The system was operated in a stepwise manner over a total of 37 separated bins, with a time 
resolution of $10 \mathrm{~min}$. For more details on the twin-DMPS system, see Kristensson et al. (2008).

\subsection{CCN counter}

The cloud nucleating properties of the aerosol was measured with a commercial CCNC (DMT model 100). The working principle of the instrument is to expose the aerosol to a fixed $s$ value, and with an Optical Particle Counter (OPC) determine the number of activated particles. The aerosol continuously flows through the center part of a cylinder with wetted walls. Between the aerosol flow and the walls, there is a particle free sheath flow. By controlling the temperature of the walls and keeping them wet (i.e. assuring that the RH is $100 \%$ just outside the cylinder wall), the migration of heat and water vapour towards the middle of the cylinder and the $s$ value can be controlled. The working principle relies on the fact that the water molecules diffuse towards the center faster than the heat added from the walls (which diffuses mainly via the heavier nitrogen and oxygen molecules), hence giving saturation ratios above $100 \%$. The $s$ values are altered in a cycle, and an activated CCN concentration as a function of $s$ is determined.

In this case the $s$ values were $0.1,0.2,0.4,0.7$ and $1 \%$, which covers basically all cloud formation $s$ values found in the atmosphere (Twomey, 1959; Warner, 1968). The activated CCN concentration is given with a time resolution of one second, but since it takes time to equilibrate the system with respect to $s$, a measurement cycle takes $\sim 30 \mathrm{~min}$.

The CCNC was calibrated in a laboratory environment before field deployment using ammonium sulphate particles with a DMA upstream the aerosol flow. The CCNC was set to a fix $s$, while the DMA selected a span of different sizes, to investigate at which size the selected particles activated. The CCNC calibration was conducted at approximately the same pressure and temperature $(70 \mathrm{~m}$ a.s.l. and $T=293 \pm 2 \mathrm{~K})$ as the field measurements $(180 \mathrm{~m}$ a.s.l. and $293 \pm 2 \mathrm{~K})$. This procedure was repeated when the $\mathrm{CCNC}$ was returned to the laboratory during the summer of 2010. For high supersaturations, the old calibration was valid within $2 \%$ down to $s=0.6$. At $s=0.25$, the CCNC measured $7 \%$ higher $s$ than indicated by the instrument, and at $s=0.2 \%$ the error was $14 \%$ in the same direction. In the field, the flows of the CCNC were monitored and checked on a weekly basis, but no salt measurements were conducted. More details on measurement uncertainties and principles of operation can be found in Rose et al. (2008).

\subsection{Petters' $\kappa$ model}

The parameter $\kappa$, first introduced by Petters and Kreidenweiss (2007), was used to describe the hygroscopicity of the aerosol. It is an ideal model, meaning that the number of soluble entities is assumed to be independent of water activity. $\kappa$ is defined according to

$\frac{1}{a_{\mathrm{w}}}=1+\kappa \frac{V_{\mathrm{s}}}{V_{\mathrm{w}}}$

Where $a_{\mathrm{w}}$ is the water activity, $V_{\mathrm{w}}$ is the water volume and $V_{\mathrm{s}}$ is the soluble volume. $\kappa$ is presently the most commonly used parameter to describe particle hygroscopicity, where values close to zero points to non-hygroscopic particles, and where values close to 1 are typical for hygroscopic aerosol, such as over marine areas. There are many differet kinds of models to describe aerosol hygroscopicity. For a review, see Rissler et al. (2010).

\subsection{CCN closure}

To validate measurement data, as well as test theoretical models and assumptions, so called "closure studies" can be performed. In principle, two or more independent measurements are linked together using relevant theoretical considerations, and in this way it is possible to indirectly evaluate if the instruments and models are consistent within errors of measurement. In this work, a CCN closure study has been carried out, comparing $\mathrm{CCNC}$ data with the predicted concentration of activated $\mathrm{CCN}(s)$ for each hour, using a combination of DMPS and H-TDMA data.

The hygroscopic growth of an aerosol particle can be derived from the Köhler equation according to

$p_{\mathrm{W}}\left(D_{p}\right)=p^{0} a_{\mathrm{w}} \exp \left(\frac{4 M_{\mathrm{w}} \sigma}{R T p_{\mathrm{w}} D_{\mathrm{w}}}\right)$

where $\rho_{\mathrm{W}}$ is the water vapour partial pressure, $p^{0}$ the saturation water vapour pressure, $a_{\mathrm{w}}$ the water activity, $M_{\mathrm{w}}$ the molar weight of water, $\sigma$ the surface tension of the solution (in this case set to $72.8 \mathrm{mN} \mathrm{m}^{-1}$ which corresponds to the surface tension of water), $R$ the universal gas constant, $T$ the temperature, $\rho_{\mathrm{w}}$ the density of water, and $D_{\mathrm{w}}$ the wet diameter. In this work we describe the hygroscopicity of the particle with the parameter $\kappa$ defined in Eq. (2). After calculating the $\kappa$ from a specific growth factor and dry size, it is possible to find the critical supersaturation, $s_{\mathrm{c}}=S_{\mathrm{c}}-1$, as described in Petters and Kreidenweiss (2007):

$\kappa=\frac{4 A^{3}}{27 D^{3} \ln ^{2} S_{\mathrm{c}}}$

where $A=\frac{4 \sigma M_{\mathrm{w}}}{R T \rho_{\mathrm{w}}}$. By combining DMPS and H-TDMA data, a prediction on the number of activated $\mathrm{CCN}$ at a certain supersaturation, $s$, can be derived. By simply summarizing up all particles with $S_{\mathrm{c}}<s$, it is possible to make a prediction regarding the number concentration of activated $\mathrm{CCN}(s)$.

For the CCN prediction, the GF-PDFs measured at 35, 50, $75,110,165$ and $265 \mathrm{~nm}$ were linearly interpolated to create 
a hygroscopic growth factor surface function $c\left(D_{\mathrm{p}}, \mathrm{GF}\right)$, where

$$
\int_{\mathrm{GF}=0}^{3} c\left(D_{\mathrm{p}}, \mathrm{GF}\right) d \mathrm{GF}=1
$$

for any given $D_{\mathrm{p}}$. For particles smaller than $35 \mathrm{~nm}$, the $35 \mathrm{~nm}$ GF-PDF was assumed to be valid. In the same way, particles larger than $265 \mathrm{~nm}$ were assumed to have GF-PDFs identical to that of $265 \mathrm{~nm}$ particles. Since every point on the function $c\left(D_{\mathrm{p}}, C_{S}\right)$ corresponds to a specific critical supersaturation, $s_{\mathrm{c}}$, the function can be rewritten as $c^{\prime}\left(D_{\mathrm{p}}, c_{s}\right)$, where

$\int_{s_{\mathrm{c}}=0}^{\infty} c^{\prime}\left(D_{\mathrm{p}}, s_{\mathrm{c}}\right) d s_{\mathrm{c}}=1$

for any given $D_{\mathrm{p}}$.

The particle size distribution is described by $a \frac{d N}{d \log D_{\mathrm{p}}}\left(D_{\mathrm{p}}\right)$ function. It is now possible to calculate the $\mathrm{CCN}$ concentration for any given $s$ value according to

$\mathrm{CCN}(s)=\int_{D_{\mathrm{p}}=3}^{850} \int_{s_{\mathrm{c}}=0}^{s} \frac{d N}{d \log D_{\mathrm{p}}}\left(D_{\mathrm{p}}\right) \cdot c^{\prime}\left(D_{\mathrm{p}, \mathrm{s}_{\mathrm{c}}}\right) d s_{\mathrm{c}} d \log D_{\mathrm{p}}$

In this case the GF integration steps were 0.05 and the $D_{\mathrm{p}}$ integration steps followed the DMPS data resolution. The calculated CCN concentration can now be compared to CCNC data, or used independently of the CCNC data, to create functions of the number of activated particles as a function of $s$.

If the $\kappa$ model accurately describes the hygroscopic behavior of the aerosol and the instruments all were ideal, the measured $\mathrm{CCNC}(s)$ concentrations would be identical to the concentrations calculated from H-TDMA and DMPS data. However, considering a number of measurement uncertainties and assumptions, certain imprecision can be expected. The linear interpolation of the GF-PDFs can be too coarse of an assumption, as can the extrapolation of the GF-PDFs corresponding to the smallest and largest particles measured by the $\mathrm{H}$ TDMA. In addition to the resolution issues of the hygroscopicity measurements, the closure will underestimate the activated $\mathrm{CCN}(s)$ concentration if there are particles present that are larger than the DMPS can detect.

Other possibilities are poor CPC calibration efficiency curves or a badly calibrated DMA flow which will affect the sizing. Problems with DMA sizing will have a more profound effect on lower $s$ values because (1) fewer particles have activated, making the relative error larger and (2) the size limit to which particles will activate is somewhere in the middle of the size distribution. At high $s$ values, a large portion of the size distribution is activated and the relative effect is smaller if you add or remove a few activated particles. In addition to this, there are often fewer particles in the size limit which is relevant to high $s$ ratios. As an example $100 \mathrm{~nm}$ particles with a GF of 1.6 activate at around $0.2 \% \mathrm{~s}$, while $40 \mathrm{~nm}$ particles with a GF of 1.3 activate at $1 \% \mathrm{~s}$.
Time resolution is another issue that introduces errors in the predicted concentration. In this aspect, the predicted concentration is limited by the H-TDMA data, which has a time resolution of $1 \mathrm{~h}$, meaning that in a worst case scenario, there will be a difference of 15 min between the H-TDMA and the $\mathrm{CCNC}$ data. Fast changes in air masses can thus give large errors in the predicted concentrations. However, seen over a longer time period, no systematical error will be introduced by this effect, but rather a slightly decreased correlation coefficient.

\section{6 $\quad \mathrm{CNN}(\mathrm{s})$ concentrations}

In models, one often wishes to describe complex phenomena in a simple but still accurate way. As shown above, calculations of the $\mathrm{CCN}$ concentration for a given aerosol is a relatively complicated and calculation. However, it is possible to simplify the calculations, by making some basic assumptions. Here, we investigated how well the $\mathrm{CCN}$ concentrations could be described assuming a size dependent average GF from H-TDMA data, as well as log-normally fitted average size distributions. Cumulative log-normal functions were used according to Seinfeld and Pandis (2006):

$N\left(D_{\mathrm{p}}\right)=\frac{N}{2}+\frac{N}{2} \operatorname{erf}\left(\frac{\log \left(D_{\mathrm{p}} / \bar{D}_{\mathrm{pg}}\right)}{\sqrt{2} \log \left(\sigma_{\mathrm{g}}\right)}\right)$

where

$\operatorname{erf}(z)=\frac{2}{\sqrt{\pi}} \int_{0}^{z} e^{-\eta 2} d \eta$

and $\bar{D}_{\mathrm{pg}}$ is the median diameter, $\sigma_{\mathrm{g}}$ is the geometric standard deviation and $N$ is the number concentration. By calculating a critical dry diameter for a certain supersaturation ratio and then integrating the size distribution from that diameter and upwards for each size mode separately, it is possible to calculate $\mathrm{CCN}(s)$.

In this work, $\mathrm{CCN}(s)$ concentration functions were produced, characteristic for the four seasons, and compared to CCNC data. The seasons were defined as follows: spring (March-May), summer (June-August), autumn (SeptemberNovember) and winter (December-February). In this case, two log-normal modes were used to fit averaged seasonal size distribution data, neglecting nucleation particle bursts. From the H-TDMA, four seasonal average sets of GF-PDFs were derived.

\section{Results}

\subsection{Data coverage}

During the full 27 months of operation, the H-TDMA data coverage varied strongly, from $10 \%$ up to $95 \%$ on a monthly basis (Table 1). The data gaps were due to power failures 
Table 1. Data coverage in percent on a monthly basis. During the full measurement period the data coverage was on average $66 \%$.

\begin{tabular}{lllllllllllll}
\hline & Jan & Feb & Mar & Apr & May & Jun & Jul & Aug & Sep & Oct & Nov & Dec \\
\hline 2008 & - & - & - & - & 79 & 16 & 51 & 56 & 52 & 88 & 63 & 68 \\
2009 & 98 & 19 & 74 & 98 & 94 & 59 & 50 & 97 & 99 & 66 & 69 & 79 \\
2010 & 74 & 13 & 53 & 83 & 97 & 79 & 47 & - & - & - & - & - \\
\hline
\end{tabular}

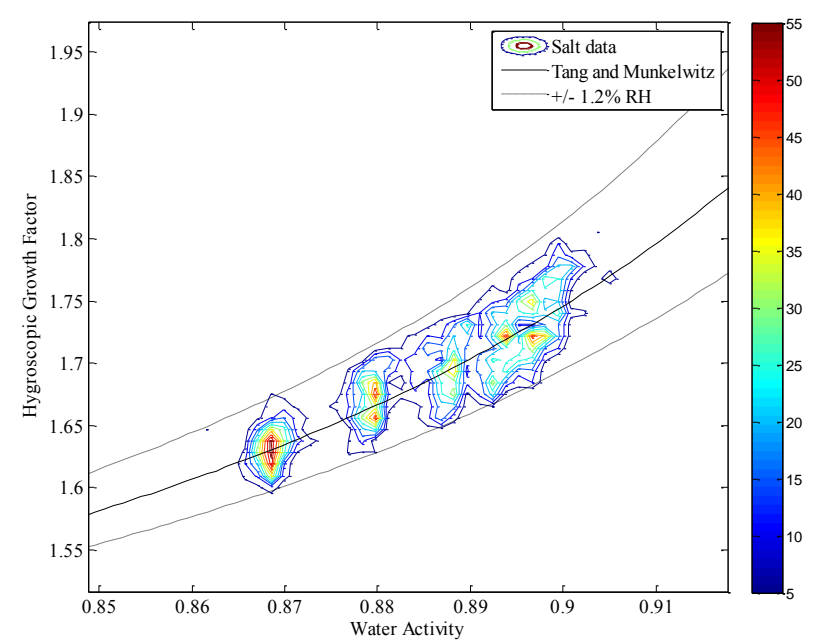

Fig. 1. Growth factor data as function of water activity and particle diameter from automated salt scans for the complete data set. The data was collected at $90 \% \mathrm{RH}$. The graph shows the density of measurement points, based on 451 days of measurements for all dry sizes. In all 4392 measurement points. The density is based on a grid of $\Delta a_{\mathrm{w}}=0.0016$ and $\Delta \mathrm{GF}=0.01$. The black line is based on data from Tang and Munkelwitz (1994) and Potukuchi and Wexler (1995). Dotted lines represent $\pm 1.2 \% \mathrm{RH}$ from this line, which is the instrument uncertainty (Nilsson et al., 2009).

and software malfunctions as well as hardware issues. Seen over the whole period of operation the data coverage was on average $66 \%$.

The data was quality checked with daily $\left(\mathrm{NH}_{4}\right)_{2} \mathrm{SO}_{4}$ scans. The results are illustrated in Fig. 1. The RH values have been recalculated to water activity, $a_{\mathrm{w}}$, adjusting for the Kelvin effect, according to Eq. (3). In this way it becomes possible to visually display different dry sizes in the same plot. As can be seen, the measured values vary from day to day but the average values are close to the values derived from data from Potukuchi and Wexler (1995) and Tang and Munkelwitz (1994), and mostly within the $\pm 1.2 \%$ which is the measurement uncertainty of the H-TDMA derived in Nilsson et al. (2009). There are a number of outliers, for which the cause of the deviation could not be determined. In these cases, data 12 hours before and after that measurement point have been discarded. These cases accounted for $\sim 3 \%$ of the scans.

\subsection{Air mass origin during measurement period}

Trajectories have been used to investigate the origin of the air masses arriving at Vavihill during the H-TDMA measurement period. This data has also been compared to trajectory data from the entire previous period when DMPS measurements have been performed at Vavihill (January 2001 to July 2010). The trajectory model Hysplit4 (Draxler and Hess, 1997) has been used to calculate the trajectories and meteorological data from the Centre of Environmental Predictions (NCEP) and GDAS (Global Data Assimilation System) archive have been used to calculate the trajectories. $72 \mathrm{~h}$ back trajectories originating at Vavihill $100 \mathrm{~m}$ a.g.l. have been used in the analysis and the centers of gravity of the trajectories have been calculated for each day. The azimuth angles and distances to the centers of gravity compared to Vavihill have then been calculated and the data divided according to season.

The results show that most air masses arrive to Vavihill from the west during all seasons and that they originate furthest from Vavihill during the winter and autumn, indicating fast moving air masses (Fig. 2). The H-TDMA measurement period May 2008 to May 2010 seem to be representative of the whole period for the spring, summer and autumn but not for the winter. The winters of 2008/2009 and 2000/2010 had fewer fast moving westerly air masses than the whole period between 2001 and 2010 and is instead dominated by slow moving air masses from the north and southeast. If the two winters are separated one can see that the winter $2008 / 2009$ is more similar to the whole period with some fast moving westerly episodes but also a lot of northerly air masses. The winter 2009/2010 is instead dominated by slowmoving south-easterly and easterly air masses with barely any air masses arriving from the west; a result of a negative North Atlantic Oscillation. This winter was associated with below average temperatures in the region and long periods with high pressure cells situated over Eastern Europe.

\subsection{Average GF-PDFs}

Figure 3a illustrates GF-PDFs for all dry sizes, averaged over the full data set (see also Table 2). Some features of the averaged GF-PDFs seem to be size dependent. Firstly, the smaller particles have a larger fraction of the GF-PDF in the barely hygroscopic and less hygroscopic part of the distribution. Secondly, the less hygroscopic mode tends to show 
Table 2. Average GF-PDFs with standard deviations for different dry sizes during the entire measurement period.

\begin{tabular}{rrrrrrr}
\hline GF & $35 \mathrm{~nm}$ & $50 \mathrm{~nm}$ & $75 \mathrm{~nm}$ & $110 \mathrm{~nm}$ & $165 \mathrm{~nm}$ & $265 \mathrm{~nm}$ \\
\hline 0.9 & $0.06 \pm 0.28$ & $0.02 \pm 0.14$ & $0.02 \pm 0.19$ & $0.02 \pm 0.17$ & $0.02 \pm 0.18$ & $0.14 \pm 0.48$ \\
1 & $0.68 \pm 1$ & $0.55 \pm 0.8$ & $0.67 \pm 0.84$ & $0.75 \pm 0.89$ & $0.59 \pm 0.74$ & $0.58 \pm 0.88$ \\
1.1 & $1.6 \pm 1.8$ & $1.26 \pm 1.54$ & $1.14 \pm 1.21$ & $0.81 \pm 0.89$ & $0.6 \pm 0.7$ & $0.64 \pm 0.79$ \\
1.2 & $1.41 \pm 1.57$ & $1.32 \pm 1.48$ & $1.12 \pm 1.33$ & $0.78 \pm 1.18$ & $0.5 \pm 0.96$ & $0.28 \pm 0.6$ \\
1.3 & $2.42 \pm 1.79$ & $2.28 \pm 1.59$ & $1.92 \pm 1.28$ & $1.37 \pm 1.12$ & $0.97 \pm 1.1$ & $0.68 \pm 1$ \\
1.4 & $2.46 \pm 2$ & $2.82 \pm 1.88$ & $2.21 \pm 1.57$ & $1.51 \pm 1.43$ & $1.12 \pm 1.25$ & $0.82 \pm 1.08$ \\
1.5 & $0.93 \pm 1.43$ & $1.4 \pm 1.65$ & $2.12 \pm 1.69$ & $2.5 \pm 1.8$ & $2.1 \pm 1.89$ & $1.37 \pm 1.67$ \\
1.6 & $0.22 \pm 0.81$ & $0.25 \pm 0.83$ & $0.64 \pm 1.14$ & $1.82 \pm 2$ & $2.85 \pm 2.29$ & $2.83 \pm 2.31$ \\
1.7 & $0.08 \pm 0.5$ & $0.07 \pm 0.48$ & $0.11 \pm 0.57$ & $0.3 \pm 0.86$ & $1.05 \pm 1.75$ & $2.1 \pm 2.35$ \\
1.8 & $0.03 \pm 0.3$ & $0.01 \pm 0.1$ & $0.03 \pm 0.28$ & $0.04 \pm 0.35$ & $0.1 \pm 0.44$ & $0.37 \pm 0.97$ \\
1.9 & $0.03 \pm 0.24$ & $0 \pm 0.05$ & $0.01 \pm 0.06$ & $0.01 \pm 0.11$ & $0.02 \pm 0.19$ & $0.09 \pm 0.45$ \\
2 & $0.01 \pm 0.1$ & $0 \pm 0.04$ & $0 \pm 0.03$ & $0 \pm 0.06$ & $0.01 \pm 0.11$ & $0.11 \pm 0.43$ \\
2.1 & $0.01 \pm 0.12$ & $0 \pm 0.04$ & $0 \pm 0.05$ & $0.02 \pm 0.15$ & $0.02 \pm 0.17$ & $0 \pm 0$ \\
2.2 & $0.02 \pm 0.1$ & $0 \pm 0.06$ & $0 \pm 0.04$ & $0.01 \pm 0.07$ & $0 \pm 0.08$ & $0 \pm 0.01$ \\
2.3 & $0 \pm 0.04$ & $0 \pm 0.02$ & $0 \pm 0.04$ & $0 \pm 0.05$ & $0 \pm 0.06$ & $0 \pm 0$ \\
2.4 & $0 \pm 0.03$ & $0 \pm 0.02$ & $0 \pm 0.04$ & $0 \pm 0.07$ & $0 \pm 0.06$ & $0 \pm 0$ \\
2.5 & $0.03 \pm 0.16$ & $0.01 \pm 0.08$ & $0.01 \pm 0.09$ & $0 \pm 0.28$ & $0.05 \pm 0.3$ & $0 \pm 0$ \\
\hline & & & & & &
\end{tabular}

Spring 2001-2010

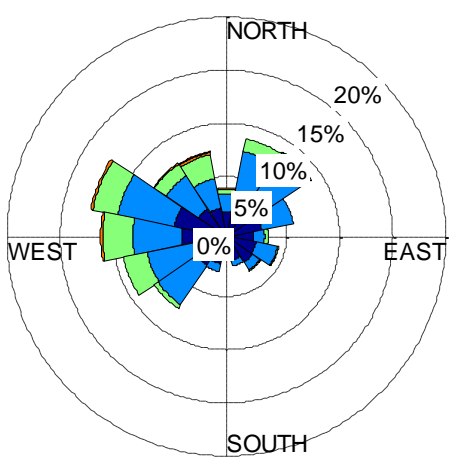

Summer 2001-2010

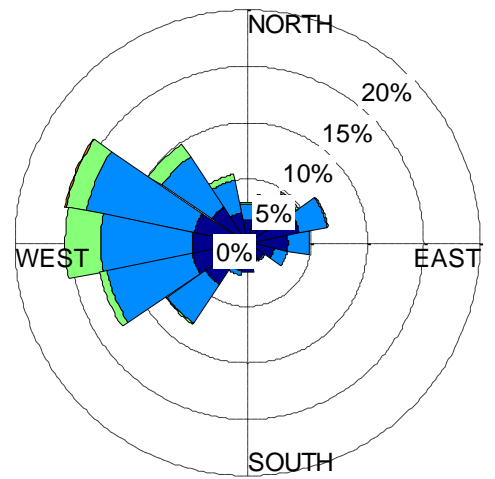

Spring 2008-2010

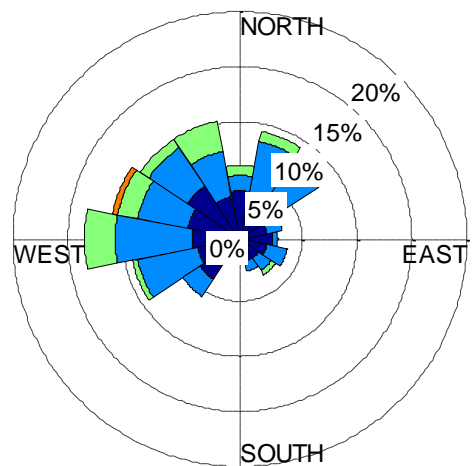

Summer 2008-2010

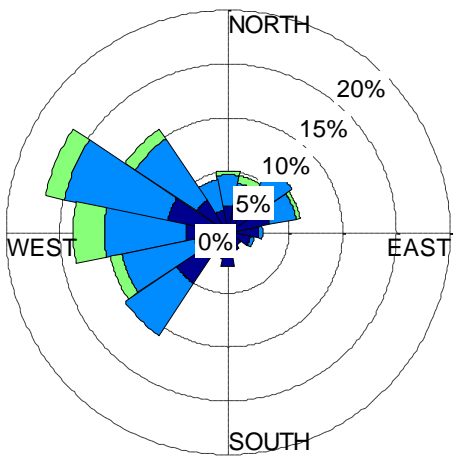

Fig. 2. Comparison between the winter 2008/2009 and the winter 2009/2010. The legend denotes distance to center of gravity in km. 
Autumn 2001-2010

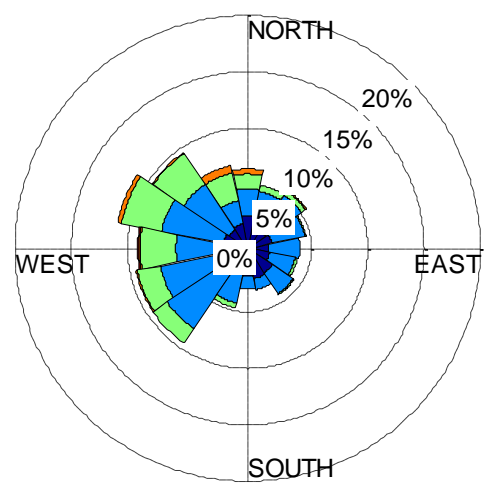

Winter 2001-2010

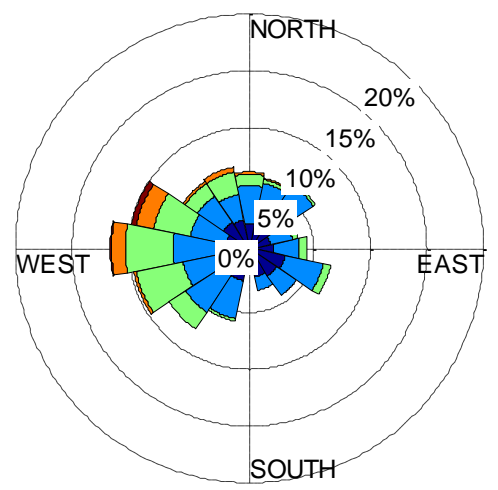

Winter 2008-2009

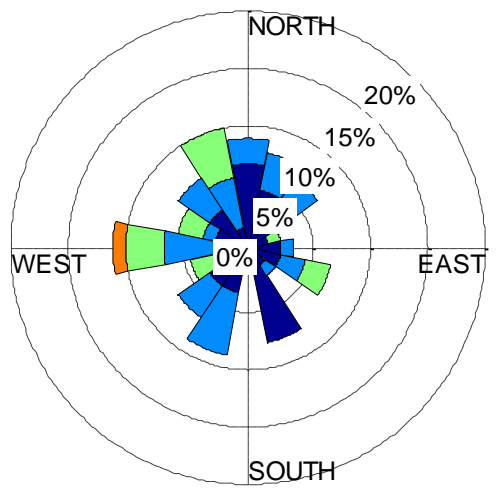

Autumn 2008-2010

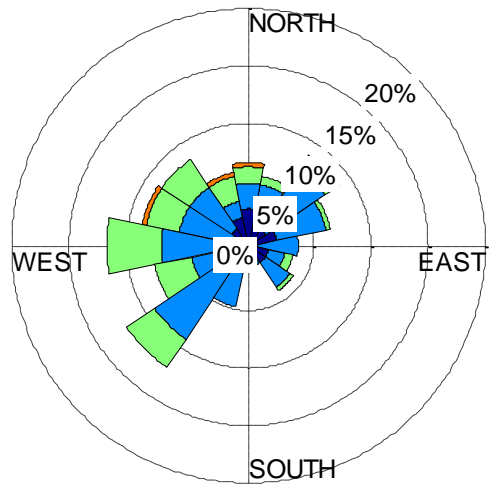

Winter 2008-2010

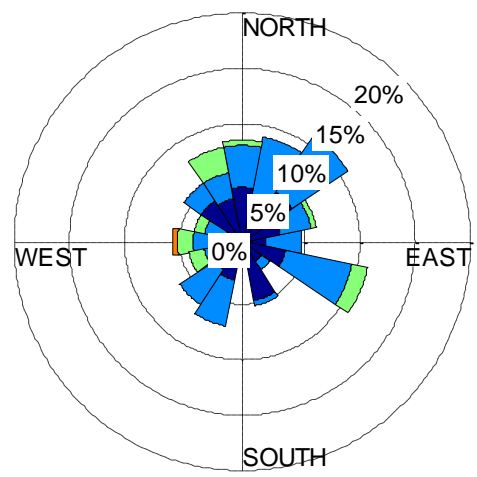

Winter 2009-2010

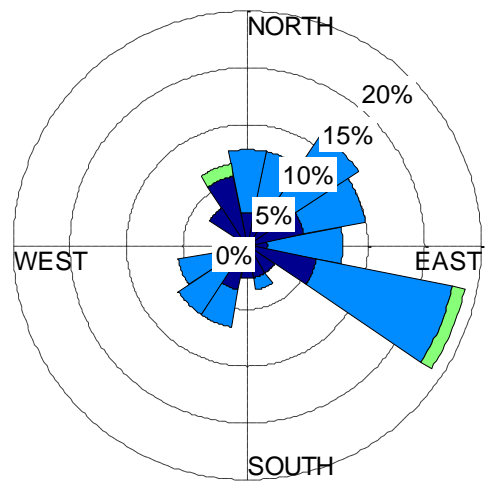

Fig. 2. Continued.

lower GFs for larger particles. Thirdly, the more hygroscopic mode tends to show higher GFs for the larger particles. This is not only because of the Kelvin effect, but because of an increased hygroscopicity in the accumulation mode compared to the Aitken mode as can be seen in Fig. $3 \mathrm{~b}$.

The fact that the solubility of the more hygroscopic mode is increasing with size can be expected and has been found in previous studies (Swietlicki et al., 2008). It is most likely due to cloud processing of the particles. The difference in hygroscopicity between the more hygroscopic 35 and $50 \mathrm{~nm}$ particles is small, and part of the difference is due to the Kelvin effect. 165 and $265 \mathrm{~nm}$ are also similar, but from 75 to $110 \mathrm{~nm}$ there is a clear increase in hygroscopicity, as this is also the size at which the transition from the non-cloud 

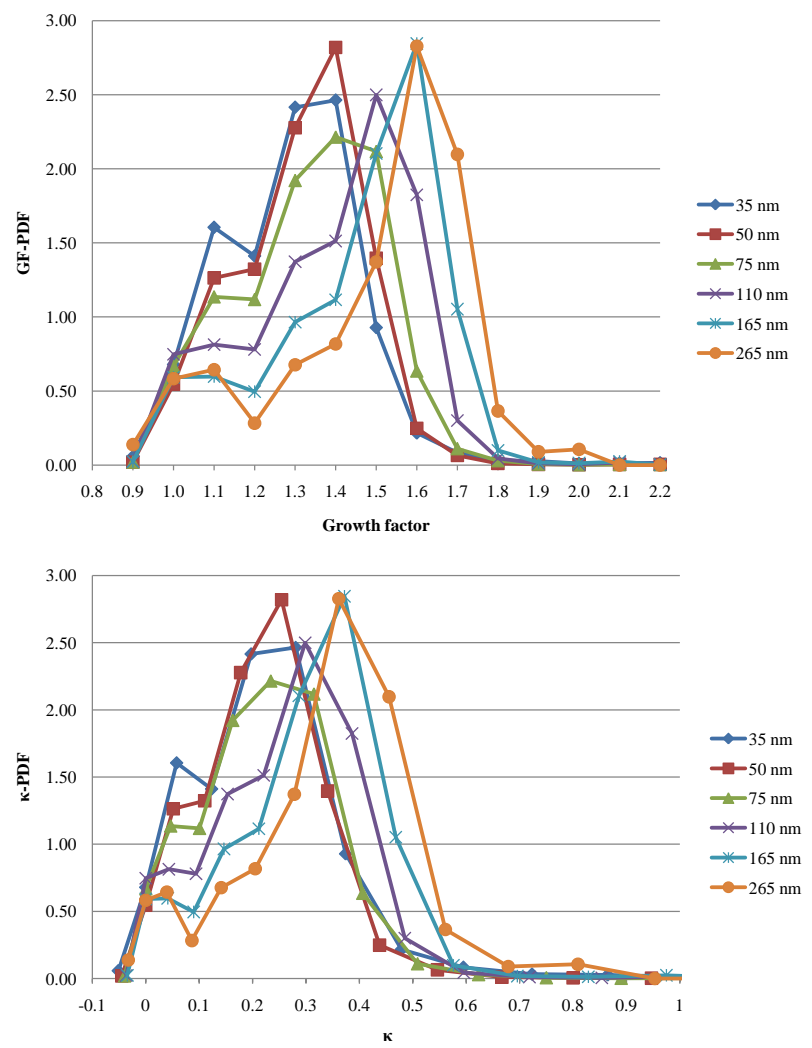

Fig. 3. Mean values of the GF-PDFs and $\kappa$-PDFs for different dry sizes for the entire data set.

processed Aitken mode to the cloud processed accumulation mode occurs.

It is important to be aware that the averaged functions can be somewhat misrepresentative. There are rarely any individual GF-PDFs with the shape of those in Fig. 3. The somewhat smeared appearance of the GF-PDFs is mostly an averaging effect. In reality the individual GF-PDFs are commonly bimodal with a clear separation of the two modes. For Aitken mode particles and below, a mono-modal distribution is more frequent than for the larger particles, and the GF-PDF is usually very dynamic, often changing several times per day. For the larger particles, the more hygroscopic mode is generally stable, while the less hygroscopic mode is more variable.

The reason for this difference is probably that the smallest particles are not as aged, and that fluctuations in meteorological conditions or air mass trajectories significantly alter particle properties. For the cloud processed particles, variations in the origin of the particles are not as important, since a large fraction of the particle consists of inorganic salts, originating from $\mathrm{NH}_{3}, \mathrm{HNO}_{3}, \mathrm{H}_{2} \mathrm{SO}_{4}$ and $\mathrm{SO}_{2}$ which are dissolved as gasses in the aerosol liquid phase. $\mathrm{SO}_{2}$ can subsequently be oxidized to $\mathrm{H}_{2} \mathrm{SO}_{4}$, primarily by $\mathrm{H}_{2} \mathrm{O}_{2}$ and these substances recombine into inorganic salts composed of $\mathrm{NH}_{4}^{+}, \mathrm{NO}_{3}^{-}, \mathrm{HSO}_{4}^{-}$and $\mathrm{SO}_{4}^{2-}$ ions, with higher hygroscopic growth factors than organic substances.

\subsection{Seasonal cycles}

As previously stated, the hygroscopic properties of ambient particles are dynamic, both on shorter and longer time scale. The seasonal variability in the average growth factor is to large extent connected to the relative abundance of less and more hygroscopic particles. Figure 4 shows monthly averaged GF-PDFs for all dry sizes. For $35 \mathrm{~nm}$ particles, it is clear that during wintertime, there is an increasing fraction of less hygroscopic particles. The growth factors of both the less and more hygroscopic modes seem to be stable over the annual cycle. There is some variation of the mode positions, but nothing that resembles an annual cycle. The $50 \mathrm{~nm}$ particles have a similar behavior to the $35 \mathrm{~nm}$ ones. They also have a clear bimodal distribution, where the relative abundance of less hygroscopic particles increases during winter, which in turn decreases the average growth factor. Also in this case it appears as if the two modes are relatively fixed in their respective growth factors.

For the $75 \mathrm{~nm}$ particles, the distribution looks slightly different. The appearing and disappearing of less hygroscopic material during winter is still visible, if not as strong, but the more hygroscopic mode is more scattered. It appears as if the distribution is tri-modal at times, but this is only an effect of the averaging. Some of the particles found in the Aitken mode are capable of activating during a cloud formation process. When this happens, as described in Sect. 4.3, they increase their hygroscopicity and the GF of the more hygroscopic mode significantly increases.

For $110 \mathrm{~nm}$ particles there are also both cloud processed and non-cloud processed particles present, and the tri-modal appearance of the $75 \mathrm{~nm}$ particles is here even more pronounced. The less hygroscopic particles are now barely hygroscopic, but still follow the seasonal pattern, being more frequent during winter. However, the relative frequency of these particles is considerably lower than for the smallest ones.

Unlike the $110 \mathrm{~nm}$ particles, there is only a weak mode of barely hygroscopic particles appearing in the GF-PDF for the 165 and $265 \mathrm{~nm}$ particles, and it only appears during wintertime. As the particle size increases into the accumulation mode, the more hygroscopic mode increases in GF, and the barely hygroscopic particles become even less hygroscopic. The reason for the appearance of particles with a GF around 1.3 in the summer for 165 and $265 \mathrm{~nm}$ diameter particles is unknown. While it might be an effect of air mass origin, it is out of scope of this paper to make a lengthy analysis of back trajectories.

To conclude, the GF-PDFs for all particle sizes measured have seasonal cycles, with a larger fraction of less hygroscopic or barely hygroscopic particles present during winter. Tables 3 and 4 summarizes the seasonal trend, both with average GFs and $\kappa$ values for each month according to Petters and Kreidenweis (2007) and with seasonal size dependent GF-PDFs. 

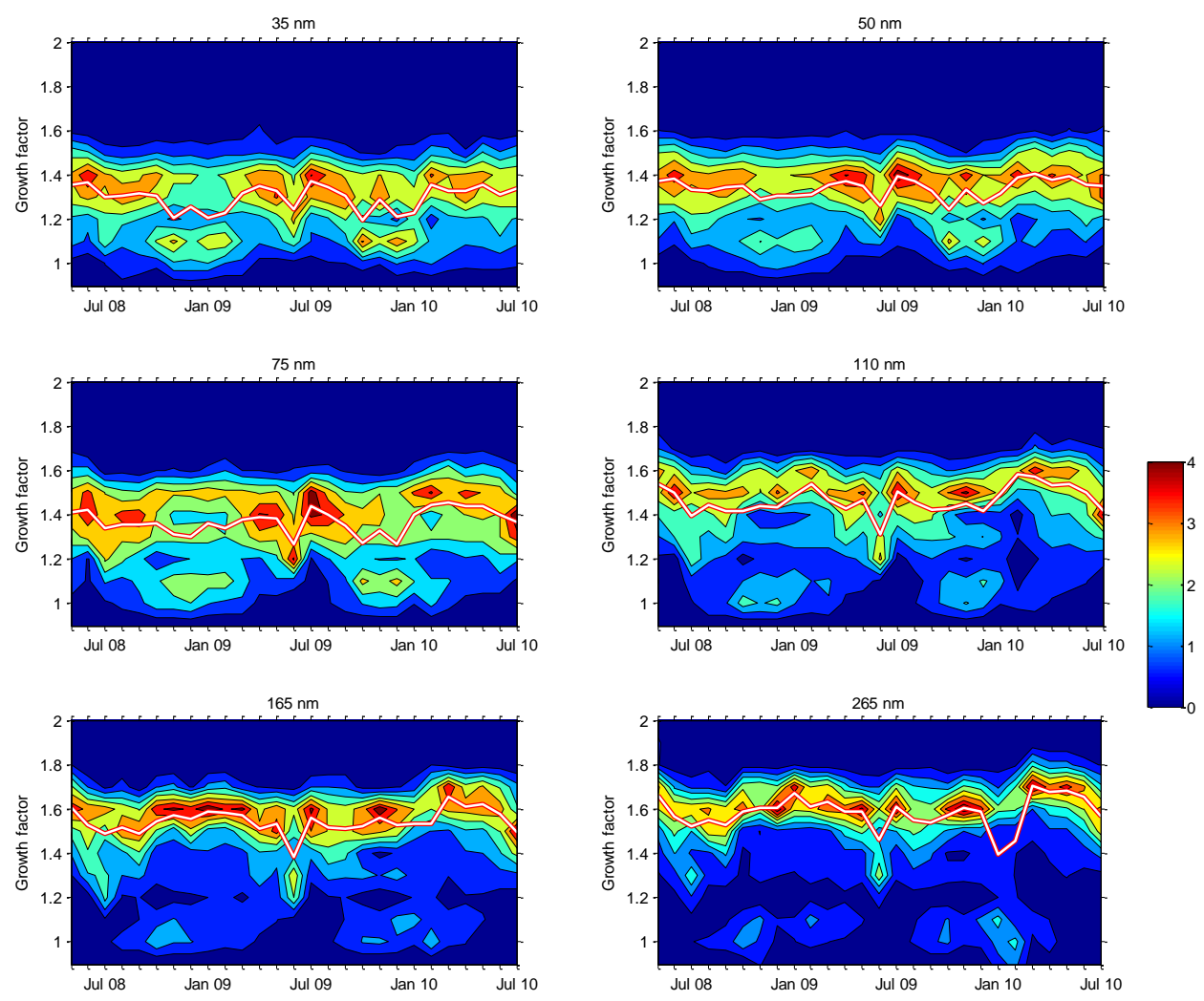

Fig. 4. Linearly interpolated contour plots of the GF-PDFs for different dry sizes based on monthly average values. The white line is the 3rd moment averaged hygroscopic growth factor.

Potential sources of the barely hygroscopic particles present during winter are not investigated in this study. However, it is likely that they originate from some form of combustion, such as residential biomass burning from wood stoves or oil burners, which are more intensively used during winter time and could produce soot particles in a wide size range. Parallel measurements of levoglucosan (Genberg et al., 2011) which is a trace element for biomass burning (Simoneit et al., 1999) confirms this by showing a strong increase during winter.

On the other hand, measurements of organic and elemental carbon (OC and EC) on the site have shown that the soot concentration is relatively stable over the year, while the OC concentration increases during wintertime. During an intensive campaign at Vavihill in October 2008, Aerosol Mass Spectrometer (AMS) data was available from the measurement site, and in a hygroscopicity closure between $\mathrm{H}$ TDMA and size resolved AMS data it was concluded that the barely hygroscopic particles found at $265 \mathrm{~nm}$ are not entirely composed of soot, as there was a clear correlation between the appearing of barely hygroscopic material and the organic fraction measured by the AMS. It is possible that the barely hygroscopic particles consist of a combination of soot and HOA.

\subsection{Diurnal cycles}

Seen over shorter periods of time, the GF-PDFs of the growth factors are highly variably, especially for the smaller particle sizes. From one hour to the next, the GF-PDF can change, due to changes in meteorological conditions as e.g. mixing layer height, temperature fluctuations, or precipitation, as well as the origin of the air mass. These changes are seemingly random, but Fourier analysis revealed a diurnal cycle in the average growth factor. When averaging the volume weighted growth factors for the full data set, it turns out that the GF peaks at noon or early afternoon (Fig. 5a). This behavior is similar for all sizes, with the exception of $265 \mathrm{~nm}$, which has its GF peak before noon. The reason for the different times of the maximum of GF for the $265 \mathrm{~nm}$ particles is not known.

The diurnal cycles found in this work are similar to those derived by e.g. Ehn et al. (2007) on freshly formed particles in boreal forest. Those particles also showed a strong diurnal cycle with GFs peaking in the afternoon for particles up to $50 \mathrm{~nm}$, although the GFs of those particles was generally lower and the amplitude of the cycle slightly higher (for $35 \mathrm{~nm}$ the Finnish boreal particles had an average growth factor of 1.2 and an amplitude (defined as the difference 
Table 3. Monthly GFs and $\kappa$ values averaged over 27 months.

\begin{tabular}{|c|c|c|c|c|c|c|c|c|c|c|c|c|}
\hline \multicolumn{13}{|c|}{ Growth factor mean } \\
\hline & Jan & Feb & Mar & Apr & May & Jun & Jul & Aug & Sep & Oct & Nov & Dec \\
\hline $35 \mathrm{~nm}$ & 1.27 & 1.30 & 1.32 & 1.33 & 1.32 & 1.31 & 1.31 & 1.30 & 1.30 & 1.27 & 1.27 & 1.27 \\
\hline $50 \mathrm{~nm}$ & 1.30 & 1.33 & 1.34 & 1.36 & 1.35 & 1.34 & 1.34 & 1.33 & 1.31 & 1.29 & 1.29 & 1.29 \\
\hline $75 \mathrm{~nm}$ & 1.35 & 1.36 & 1.37 & 1.39 & 1.39 & 1.37 & 1.37 & 1.35 & 1.33 & 1.31 & 1.31 & 1.30 \\
\hline $110 \mathrm{~nm}$ & 1.41 & 1.45 & 1.44 & 1.42 & 1.45 & 1.42 & 1.41 & 1.40 & 1.37 & 1.37 & 1.38 & 1.37 \\
\hline $165 \mathrm{~nm}$ & 1.47 & 1.46 & 1.51 & 1.48 & 1.52 & 1.47 & 1.47 & 1.47 & 1.44 & 1.45 & 1.46 & 1.44 \\
\hline $265 \mathrm{~nm}$ & 1.49 & 1.44 & 1.58 & 1.54 & 1.57 & 1.51 & 1.50 & 1.50 & 1.48 & 1.50 & 1.52 & 1.52 \\
\hline \multicolumn{13}{|c|}{ Growth factor median } \\
\hline $35 \mathrm{~nm}$ & 1.27 & 1.31 & 1.32 & 1.33 & 1.33 & 1.30 & 1.31 & 1.31 & 1.30 & 1.28 & 1.28 & 1.28 \\
\hline $50 \mathrm{~nm}$ & 1.31 & 1.34 & 1.35 & 1.36 & 1.35 & 1.33 & 1.34 & 1.34 & 1.32 & 1.31 & 1.30 & 1.30 \\
\hline $75 \mathrm{~nm}$ & 1.35 & 1.37 & 1.37 & 1.39 & 1.39 & 1.36 & 1.36 & 1.36 & 1.33 & 1.32 & 1.31 & 1.31 \\
\hline $110 \mathrm{~nm}$ & 1.42 & 1.46 & 1.43 & 1.43 & 1.46 & 1.41 & 1.41 & 1.41 & 1.38 & 1.38 & 1.38 & 1.37 \\
\hline $165 \mathrm{~nm}$ & 1.49 & 1.47 & 1.51 & 1.49 & 1.53 & 1.45 & 1.47 & 1.47 & 1.44 & 1.46 & 1.46 & 1.44 \\
\hline $265 \mathrm{~nm}$ & 1.51 & 1.45 & 1.59 & 1.54 & 1.58 & 1.50 & 1.52 & 1.50 & 1.48 & 1.51 & 1.53 & 1.52 \\
\hline \multicolumn{13}{|c|}{ Growth factor std } \\
\hline $35 \mathrm{~nm}$ & 0.10 & 0.08 & 0.08 & 0.09 & 0.10 & 0.11 & 0.09 & 0.09 & 0.10 & 0.09 & 0.08 & 0.09 \\
\hline $50 \mathrm{~nm}$ & 0.08 & 0.07 & 0.07 & 0.09 & 0.10 & 0.10 & 0.09 & 0.08 & 0.09 & 0.08 & 0.07 & 0.08 \\
\hline $75 \mathrm{~nm}$ & 0.07 & 0.06 & 0.07 & 0.09 & 0.10 & 0.10 & 0.09 & 0.08 & 0.08 & 0.08 & 0.06 & 0.06 \\
\hline $110 \mathrm{~nm}$ & 0.09 & 0.12 & 0.08 & 0.08 & 0.11 & 0.11 & 0.10 & 0.09 & 0.08 & 0.08 & 0.07 & 0.07 \\
\hline $165 \mathrm{~nm}$ & 0.10 & 0.11 & 0.07 & 0.09 & 0.11 & 0.12 & 0.12 & 0.10 & 0.09 & 0.09 & 0.08 & 0.08 \\
\hline $265 \mathrm{~nm}$ & 0.12 & 0.11 & 0.08 & 0.10 & 0.10 & 0.11 & 0.11 & 0.09 & 0.10 & 0.11 & 0.09 & 0.09 \\
\hline \multicolumn{13}{|l|}{$\kappa$ mean } \\
\hline $35 \mathrm{~nm}$ & 0.16 & 0.18 & 0.20 & 0.21 & 0.20 & 0.19 & 0.19 & 0.19 & 0.18 & 0.16 & 0.16 & 0.16 \\
\hline $50 \mathrm{~nm}$ & 0.17 & 0.19 & 0.20 & 0.21 & 0.20 & 0.20 & 0.20 & 0.19 & 0.18 & 0.16 & 0.16 & 0.16 \\
\hline $75 \mathrm{~nm}$ & 0.19 & 0.20 & 0.21 & 0.22 & 0.22 & 0.21 & 0.20 & 0.19 & 0.17 & 0.17 & 0.16 & 0.16 \\
\hline $110 \mathrm{~nm}$ & 0.22 & 0.26 & 0.24 & 0.23 & 0.26 & 0.24 & 0.23 & 0.22 & 0.20 & 0.20 & 0.20 & 0.19 \\
\hline $165 \mathrm{~nm}$ & 0.26 & 0.25 & 0.29 & 0.27 & 0.30 & 0.26 & 0.26 & 0.26 & 0.24 & 0.24 & 0.25 & 0.24 \\
\hline $265 \mathrm{~nm}$ & 0.28 & 0.24 & 0.34 & 0.31 & 0.34 & 0.29 & 0.28 & 0.28 & 0.26 & 0.28 & 0.29 & 0.29 \\
\hline \multicolumn{13}{|c|}{$\kappa$ median } \\
\hline $35 \mathrm{~nm}$ & 0.16 & 0.19 & 0.20 & 0.20 & 0.20 & 0.18 & 0.19 & 0.19 & 0.18 & 0.17 & 0.17 & 0.17 \\
\hline $50 \mathrm{~nm}$ & 0.17 & 0.19 & 0.20 & 0.21 & 0.20 & 0.19 & 0.19 & 0.19 & 0.18 & 0.17 & 0.17 & 0.17 \\
\hline $75 \mathrm{~nm}$ & 0.19 & 0.20 & 0.20 & 0.21 & 0.21 & 0.20 & 0.20 & 0.19 & 0.18 & 0.17 & 0.16 & 0.16 \\
\hline $110 \mathrm{~nm}$ & 0.22 & 0.26 & 0.24 & 0.23 & 0.26 & 0.22 & 0.22 & 0.22 & 0.20 & 0.20 & 0.20 & 0.19 \\
\hline $165 \mathrm{~nm}$ & 0.27 & 0.26 & 0.29 & 0.27 & 0.30 & 0.24 & 0.26 & 0.26 & 0.24 & 0.25 & 0.25 & 0.24 \\
\hline $265 \mathrm{~nm}$ & 0.29 & 0.24 & 0.35 & 0.31 & 0.34 & 0.27 & 0.29 & 0.28 & 0.26 & 0.28 & 0.30 & 0.29 \\
\hline \multicolumn{13}{|l|}{$\kappa$ std } \\
\hline $35 \mathrm{~nm}$ & 0.07 & 0.06 & 0.06 & 0.07 & 0.07 & 0.08 & 0.06 & 0.06 & 0.07 & 0.06 & 0.05 & 0.06 \\
\hline $50 \mathrm{~nm}$ & 0.06 & 0.05 & 0.05 & 0.06 & 0.07 & 0.07 & 0.06 & 0.06 & 0.06 & 0.05 & 0.05 & 0.05 \\
\hline $75 \mathrm{~nm}$ & 0.05 & 0.04 & 0.05 & 0.06 & 0.07 & 0.07 & 0.06 & 0.05 & 0.05 & 0.05 & 0.04 & 0.04 \\
\hline $110 \mathrm{~nm}$ & 0.06 & 0.07 & 0.06 & 0.06 & 0.08 & 0.08 & 0.07 & 0.06 & 0.05 & 0.05 & 0.05 & 0.05 \\
\hline $165 \mathrm{~nm}$ & 0.07 & 0.06 & 0.06 & 0.07 & 0.09 & 0.09 & 0.08 & 0.07 & 0.06 & 0.06 & 0.06 & 0.06 \\
\hline $265 \mathrm{~nm}$ & 0.08 & 0.08 & 0.07 & 0.08 & 0.08 & 0.09 & 0.09 & 0.07 & 0.07 & 0.09 & 0.07 & 0.07 \\
\hline
\end{tabular}

between maximum and minimum value) of 0.15 while our study found an average growth factor of 1.3 and an amplitude of 0.08). Other studies that have found the same type of diurnal trend with GF maxima in day time and minimum at night are Hämeri et al. (2001), Boy et al. (2004) and Petäjä et al. (2005). All these studies were conducted in boreal forest at the SMEAR II station in Hyytiälä, Finland.

In this study, most of the difference in GFs for 35, 50 and $75 \mathrm{~nm}$ can be explained by the Kelvin effect, and when recalculating the growth factors to $\kappa$ values, the hygroscopicity 
Table 4. Seasonal averaged GF-PDFs with corresponding standard deviations.

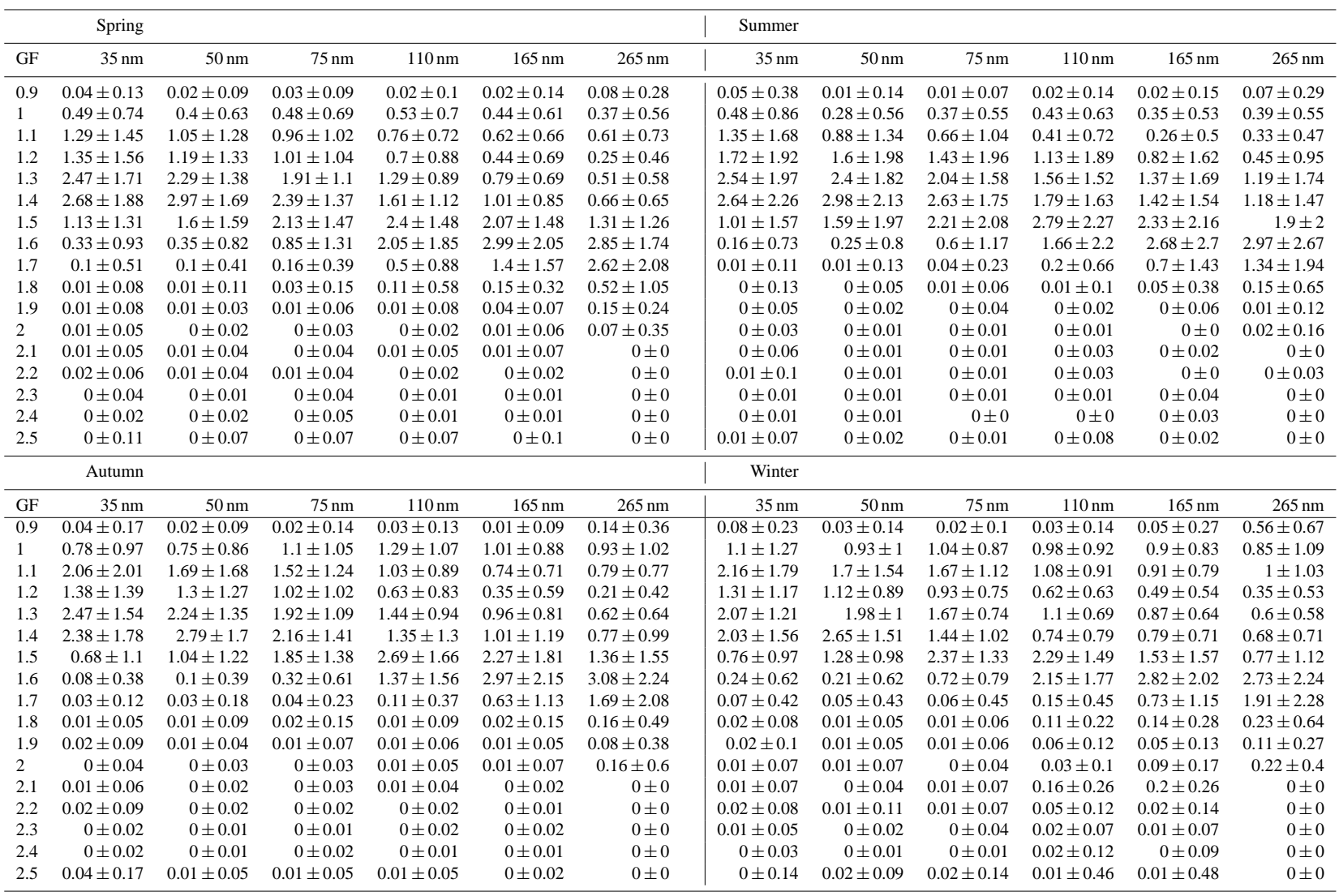

of the three smallest sizes were in principle identical, which can be interpreted as if they had the same chemical composition (Fig. 5b). It can be noted that the $35 \mathrm{~nm}$ particles are slightly more hygroscopic than the 50 and $75 \mathrm{~nm}$ particles. The reason for this is unknown.

There are a number of possible reasons for the diurnal cycle in hygroscopicity. One is the diurnal evolution of the planetary boundary layer (PBL) as discussed in e.g. Rissler et al. (2006). In the morning, when the sun rises, the PBL increases in height and older particles are mixed down. In general, older particles are more hygroscopic, due to both an increased fraction of cloud processed particles, and to the fact that aging of the organic fraction in form of photolysis and oxidation increases its hygroscopicity (Jimenez et al., 2009). For these reasons, the average particle will become more and more hygroscopic as the boundary layer increases in height. When the sun sets and the boundary layer collapses, local particle sources will have a bigger influence than they would have had during daytime, due to the low mixing height.

Nucleation mode particles have relatively short lifetimes. They either grow into the Aitken mode or coagulate with larger particles, which means that the diurnal cycle of the boundary layer will have less of an effect on the hygroscopicity of small particles compared to larger ones. Apart from these meteorological considerations, partitioning of semivolatile species will follow the temperature which in turn follows the diurnal cycle. Primarily it is $\mathrm{NO}_{3}$ (in the form of $\mathrm{HNO}_{3}$ ) and semi-volatile organic species that follow a diurnal cycle (Lanz et al., 2007; Raatikainen et al., 2010). $\mathrm{HNO}_{3}$ dissolves in water and forms inorganic salts with relatively high GFs, which means that daytime evaporation will lead to a decrease in hygroscopicity. Evaporation of semivolatile organics will on the other hand lead to an increased hygroscopicity, since the average hygroscopicity of the particle generally is higher than the organics which evaporates.

AMS measurements carried out at Vavihill during October 2008 confirm strong diurnal cycles in organic mass ratios as well as $\mathrm{NO}_{3}$, but the $\mathrm{NO}_{3}$ was only found in sizes larger than $80 \mathrm{~nm}$ with a strongly increasing volume fraction with increasing particle size. For particles below $80 \mathrm{~nm}$, the aerosol mass consisted almost exclusively of organics and small amounts $(\sim 10 \%)$ of $\left(\mathrm{NH}_{4}\right)_{2} \mathrm{SO}_{4}$. With this in mind, it seems likely that the diurnal cycle seen for the $35 \mathrm{~nm}$ particles is at least partially driven by condensation and evaporation of organics.

Finally, diurnal cycles in the aerosol can be attributed to diurnal patterns of local sources. E.g. car emissions typically show peak values during rush hours. Massling et al. (2005) 

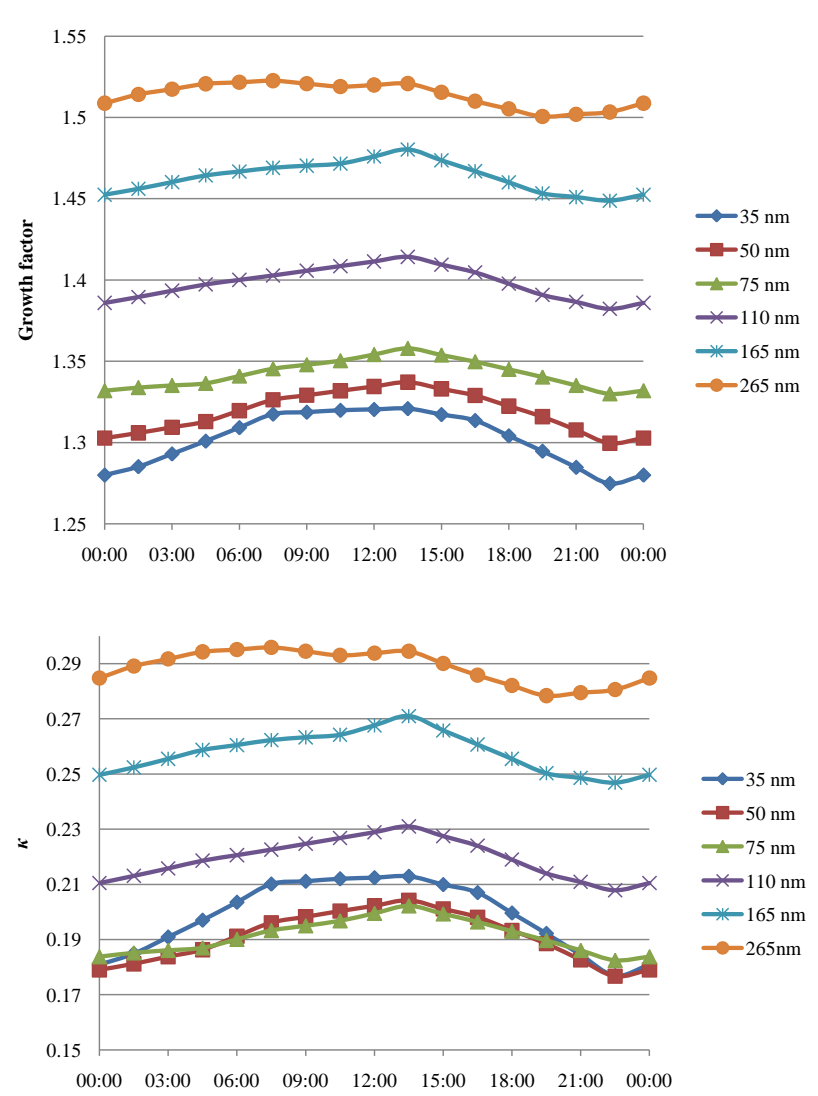

Fig. 5. Diurnal variation for the full data set for the different dry sizes. (a) illustrates the growth factor variation and (b) the variation in $\mathrm{a} \kappa$.

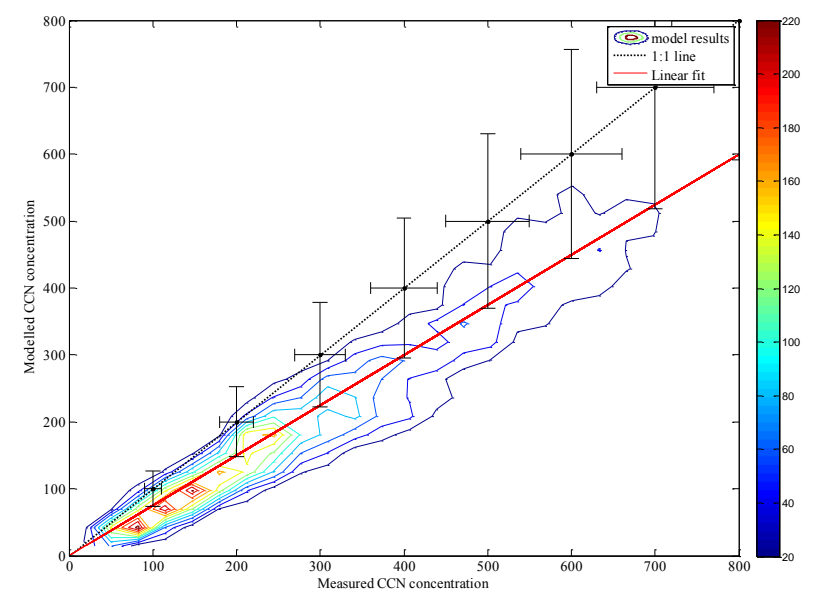

Fig. 6. Correlation between measured and modeled CCN concentrations for $0.1 \%$ supersaturation. The model slightly underpredicts the number of $\mathrm{CCN}$, and the tendency is increasing with decreasing $s_{\mathrm{c}}$. The dotted line is the 1:1 line, and the grey error bars represent a $10 \%$ relative uncertainty in the $s$ from the CCNC (x-axis) and the error propagation described in Sect. 4.6 (y-axis) respectively.

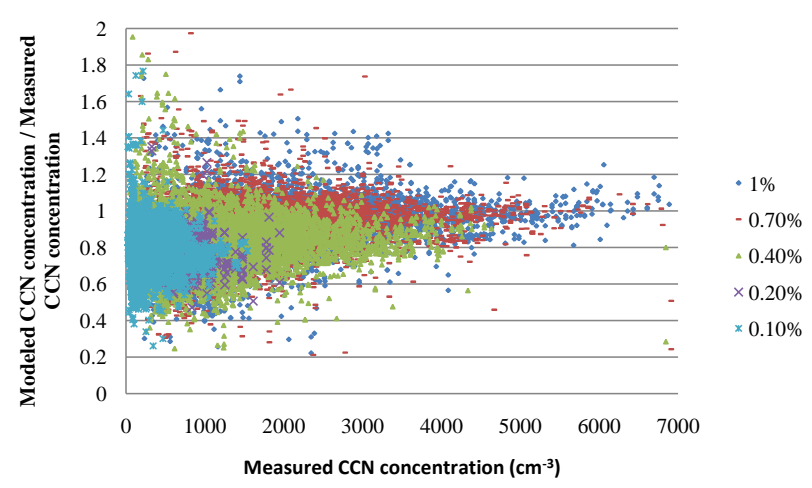

Fig. 7. Ratio of modeled to measured CCN concentration for five different $s$ ratios.

found a clear peak in barely hygroscopic particles during morning rush hours at an urban measurement site. However, this pattern could not be found at the background station used for this study.

There was no clear annual pattern found in the amplitude of the diurnal GF cycle in any of the dry sizes. This would have been expected if variation in boundary layer height was the dominating effect, since the variation of the boundary layer height is strongly dependent on season. Instead we noted seemingly random monthly variations, most likely due to changes in meteorological conditions, and with the amplitude consistently higher for the smaller particles.

\subsection{CCN closure}

The CCN closure was carried out for the full data set for five different supersaturation ratios: $0.1,0.2,0.4,0.7$ and $1 \%$. Figure 6 illustrates the scatter plot of $0.1 \% s$ and Fig. 7 illustrates the ratio of predicted and measured $\mathrm{CCN}$ concentrations for all $s$ ratios. Table 5 presents the slope coefficients for all $s$ closures. The $\kappa$-model consistently predicted a lower $\mathrm{CCN}$ concentration than the CCNC. While the coefficient of determination was very similar for all cases $(0.92 \pm 0.02)$, the slope of the regression line varied from 0.71 for $0.2 \%$ supersaturation to 0.95 for $1 \%$ supersaturation. The reason for this is not known, but a number of possible explanations can be hypothesized.

The CPCs used in the DMPS system have been calibrated using Ag particles and the calibration curves are used in the DMPS system in order not to underestimate the particle concentration. However, during an intercomparison workshop in March 2008 at the Institute for Atmospheric Research, IFT in Leipzig, the DMPS used in this closure measured $15 \%$ lower concentration than a CPC (TSI 3010) that was measuring total particle concentration simultaneously.

If this underprediction in number concentration is always present, it will lead to an underestimation of the $\mathrm{CCN}(s)$ concentration. However, when comparing the full DMPS size distribution to the measured $\mathrm{CCN}$ concentration at $1 \%$ 
$\mathrm{s}$, which is the highest $s$ value, the maximum $\mathrm{CCN}(s)$ values match the DMPS concentration well (Fig. 8), a fact that contradicts the counting efficiency of the $\mathrm{CCN}$ as the major problem in the closure. Of course there is also the possibility of the H-TDMA underestimating the particle hygroscopicity or the DMPS selecting the wrong sizes. Assuming that all instruments are functioning properly, it is the model that is incorrect. There are numerous other static CCN models in the literature, and Rissler et al. (2010) found that they gave 6-10\% difference in predicted $\mathrm{CCN}$ concentrations using seven different approaches for two different model aerosols. It should be stressed that the model used in this work does not include any non-ideal effects which can potentially increase the hygroscopicity when increasing the water activity.

The fact that the underprediction is stronger for low sratios in this work can be explained by the fact that there are fewer particles in the sizes range which are close to activation at $1 \%$ (nucleation mode) than there is at $0.2 \%$ (Aitken or accumulation mode). An underestimation of the hygroscopicity would therefore have a larger impact at 0.2 than at $1 \% \mathrm{~s}$. The uncertainty of the $s$ measured by the CCNC also tends to increase for lower $s$ (see e.g. Rose et al. (2008)). To investigate the uncertainty introduced by error propagation from different measurement parameters, we used the precision of size distribution measurements from Wiedensohler et al. (2010) who compared a number of SMPS and DMPS systems in a laboratory environment and concluded that most systems measure a total particle concentration $\pm 10 \%$ while the sizing of the particles can be expected to be accurate with $\pm 3.5 \%$. In addition to this, the H-TDMA is estimated to measure growth factors within $3 \%$ precision in GF due to uncertainties in the RH measurement.

For simplification, we used the average GF-PDFs and the average size distribution for the entire measurement period and calculated the relative change in predicted $\mathrm{CCN}$ concentrations for $0.1,0.2,0.4,0.7$ and $1 \% s$. The shape of the size distribution makes the uncertainty very varying (see Table 6). For allsexcept $0.2 \% s$, the summarized measurement uncertainties can hypothetically explain the difference in measured and predicted $\mathrm{CCN}$ concentration. For $0.2 \%$ however, there is still a difference of $7 \%$, even after introducing all measurement uncertainty. An additional uncertainty in the CCNC could possibly explain the last percent. Even though the instrument calibration was checked after the campaign, more frequent salt calibration of the CCNC should have been carried out in order to fully trust the $\mathrm{CCN}$ concentrations. Investigation showed no long term trend in the ratio of modeled to measured CCN concentration, which indicates that the calibration did not drift significantly, but direct salt scans would significantly increase the reliability of the CCNC data.

Another measurement artifact that might play a role is that particles may not have reached their equilibrium with respect to the surrounding water vapour. Firstly, the aerosol must be completely dry when it enters DMA1. If it is not, and it keeps shrinking until it reaches the humidifier, the GF will

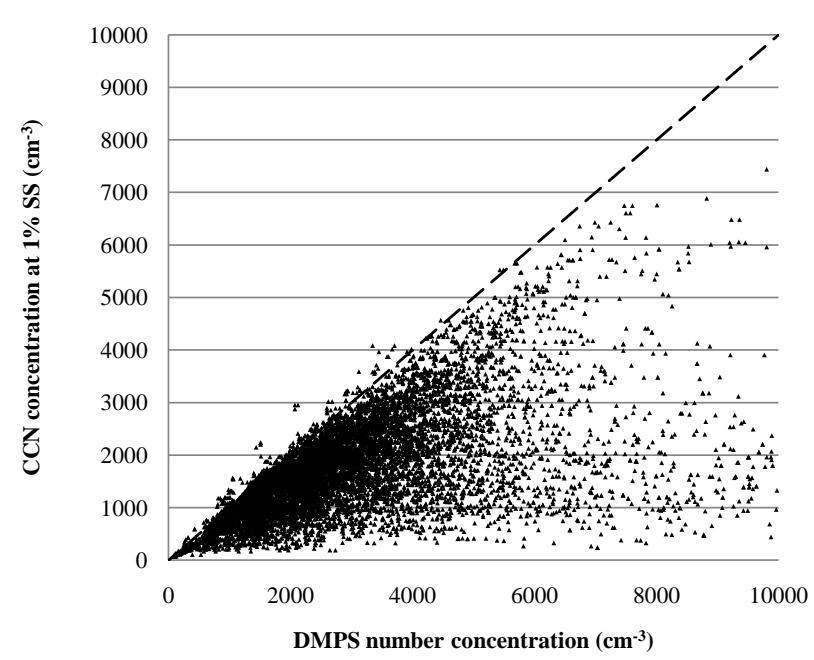

Fig. 8. Particle concentration from DMPS and CCNC measuring at $1 \% s$. The dotted line is the 1:1-line.

Table 5. CCN closure coefficients for four different supersaturation ratios.

\begin{tabular}{rrr}
\hline $\begin{array}{r}\text { Critical } \\
\text { supersaturation, } \\
S_{\mathrm{c}}(\%)\end{array}$ & $\begin{array}{r}k\left(\mathrm{CCN}_{\text {modeled }} /\right. \\
\left.\mathrm{CCN}_{\text {measured }}\right)\end{array}$ & $\begin{array}{r}\text { Coefficient } \\
\text { of determination, } \\
R^{2}\end{array}$ \\
\hline 1 & 0.94 & 0.92 \\
0.7 & 0.92 & 0.92 \\
0.4 & 0.82 & 0.93 \\
0.2 & 0.71 & 0.94 \\
0.1 & 0.73 & 0.9 \\
\hline
\end{tabular}

be underestimated. In the same manner, if it does not reach the humidified diameter before entering DMA2, the GF will be further underestimated. These two effects will both lead to an underestimation of the $\mathrm{CCN}$ concentration, especially atsvalues corresponding to diameters in the middle of the size distribution. Finally, drying of the aerosol in the DMPS can play a role. If the particles are not completely dried out, the sizes will be overestimated, which will lead to an overestimation of the $\mathrm{CCN}$ concentration.

In addition to measurement uncertainties, aerosol properties can play a role. It is possible that compounds as $\mathrm{K}_{2} \mathrm{SO}_{4}$ which have a limited solubility will lead to an overestimation of the $S_{\mathrm{c}}$ or that there are particles larger present then what is measured by the DMPS, something that would play a larger role for low $s$ values. Another possibility is that the particles contain surface active compounds such as HULIS, which has been proposed to originate from polymerization in the aqueous phase, formed through ageing of particles (Graber and 
Table 6. Change in correlation slope taking into account a size error of $\pm 3.5 \%$, a counting error of $\pm 10 \%$ and an H-TDMA GF error of $3 \%$.

\begin{tabular}{|c|c|c|}
\hline$s(\%)$ & $\begin{array}{r}\text { Number conc., } \\
\text { GF and size } \\
\text { overestimated }(\%)\end{array}$ & $\begin{array}{r}\text { Number conc., } \\
\text { GF and size } \\
\text { underestimated }(\%)\end{array}$ \\
\hline 1 & 17.7 & -22.2 \\
\hline 0.7 & 18.8 & -19 \\
\hline 0.4 & 19.2 & -24.2 \\
\hline 0.2 & 29.3 & -19 \\
\hline 0.1 & 26.7 & -25.9 \\
\hline
\end{tabular}

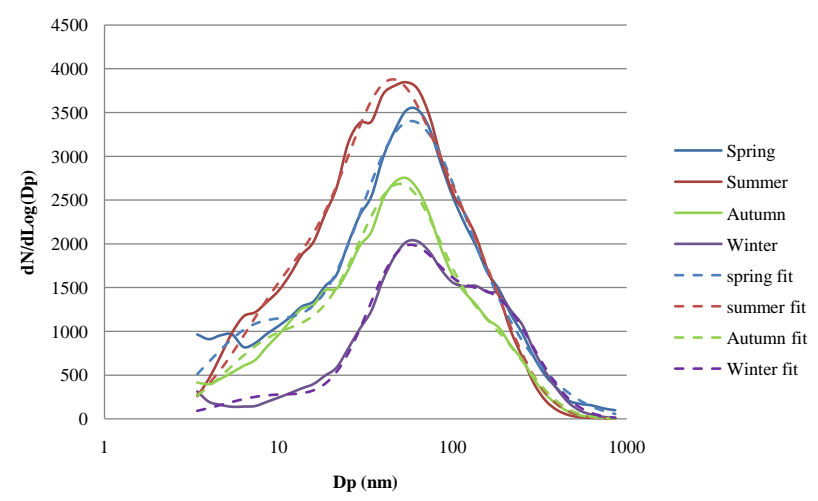

Fig. 9. Seasonal average size distributions from DMPS data and three mode log-normal fits.

Rudich, 2006). When altering the surface tension, it was concluded that a surface tension of $\sim 55 \mathrm{mN} \mathrm{m}^{-1}$ is required to reach a perfect closure. No seasonal or diurnal cycle was found in the ratio of modeled to measured CCN concentrations. Distinct periods of different ratios were found, rather than the continuous change that one might expect from e.g. seasonal sources such as biogenic SOA or combustion particles from heating.

This underprediction of $\mathrm{CCN}$ concentrations based on subsaturated measurements has to our knowledge not been found in previous CCN closure studies, which indicates that it is in fact a measurement effect rather than an aerosol effect. Moreover, previously published CCN closure studies have tended to overestimate the number of CCN (Kammermann et al., 2010b; McFiggans et al., 2006).

\section{7 $\mathrm{CCN}(s)$ concentrations}

Finally, $\mathrm{CCN}(s)$ concentration functions were derived, based on seasonal averages and compared to seasonal CCNC data (Table 7). Average DMPS size distribution spectrums for the four seasons were derived (Fig. 9), as well as seasonal average GF-PDFs for the different dry sizes. A modal fit routine was then applied to describe the average distribution with three log-normal modes (Hussein et al., 2005) (Table 8). The mode with smallest particle diameter, if GMD was smaller than $20 \mathrm{~nm}$, was then excluded for each season. The reason for this was to avoid bias from frequently occurring nucleation bursts when comparing the fraction of activated particles for a specific $s$. For more details on the number size distribution of Vavihill, see Kristensson et al. (2008).

The averaged and mode-fitted size distributions were used to calculate $\mathrm{CCN}(s)$ for different seasons applying two different approaches: (1) Using the full external mixture of the aerosol, and (2) Calculating size dependent GFs from 3rd moment averaged GF-PDFs, and linearly interpolating to the geometric mean values of the fitted log-normal distributions. From this data the cumulative log-normal distribution described in Sect. 3.5 was used to calculate $\mathrm{CCN}(s)$ functions. It was found that the second approach produced $\mathrm{CCN}(s)$ functions very similar to taking the full GF-PDF into account (Fig. 10a-d).

For $1 \% s, \mathrm{CCN}$ concentrations were highest during summer and spring, followed by autumn, and the lowest concentration was found during winter. This can partially be attributed to the concentration of Aitken mode particles, which largely follow the same order, and partially by the hygroscopic growth, which was found to be higher during summertime. For lower $s$ ratios, winter showed the highest CCN concentration, due to a larger accumulation mode, followed by summer and spring and finally autumn, which presented the lowest $\mathrm{CCN}$ concentration.

Considering the high STD values of the seasonally averaged $\mathrm{CCN}$ concentrations, it can be concluded that the $\mathrm{CCN}(s)$ functions derived from averaged DMPS and $\mathrm{H}-$ TDMA data well describe the CCN concentrations for different seasons, and that the assumption of an internally mixed aerosol with respect to hygroscopic properties in this case was adequate for describing the $\mathrm{CCN}(s)$ concentration of a European continental background aerosol.

\section{Summary and conclusions}

Hygroscopic properties of the aerosol at the background EUSAAR supersite Vavihill has been measured over a period of 27 months. H-TDMA data has been analysed with respect to temporal variability with focus both on seasonal and diurnal cycles. A CCN closure study has been carried out and $\mathrm{CCN}(s)$ concentration functions for different seasons have been produced.

In general, the aerosol was often externally mixed with respect to hygroscopic growth, with GFs of both the less hygroscopic and more hygroscopic modes varying in time. Smaller particles were found to have a higher fraction of less hygroscopic particles. There is also a trend of increasing separation between the two hygroscopic modes with increasing size. The high GFs of the larger particles can most likely be attributed to a combination of chemical ageing and cloud 
Table 7. Seasonal average CCN concentrations $\left(\mathrm{cm}^{-3}\right)$ with standard deviations from the DMT CCNC.

\begin{tabular}{lrrrrr}
\hline$s_{\mathrm{c}}(\%)$ & 0.1 & 0.2 & 0.4 & 0.7 & 1 \\
\hline Spring & $372 \pm 269$ & $751 \pm 491$ & $1183 \pm 713$ & $1563 \pm 865$ & $1828 \pm 971$ \\
Summer & $322 \pm 168$ & $792 \pm 448$ & $1298 \pm 714$ & $1775 \pm 879$ & $2093 \pm 988$ \\
Autumn & $291 \pm 235$ & $595 \pm 511$ & $946 \pm 774$ & $1319 \pm 1116$ & $1573 \pm 1129$ \\
Winter & $421 \pm 267$ & $705 \pm 448$ & $973 \pm 608$ & $1221 \pm 719$ & $1379 \pm 785$ \\
\hline
\end{tabular}

a)
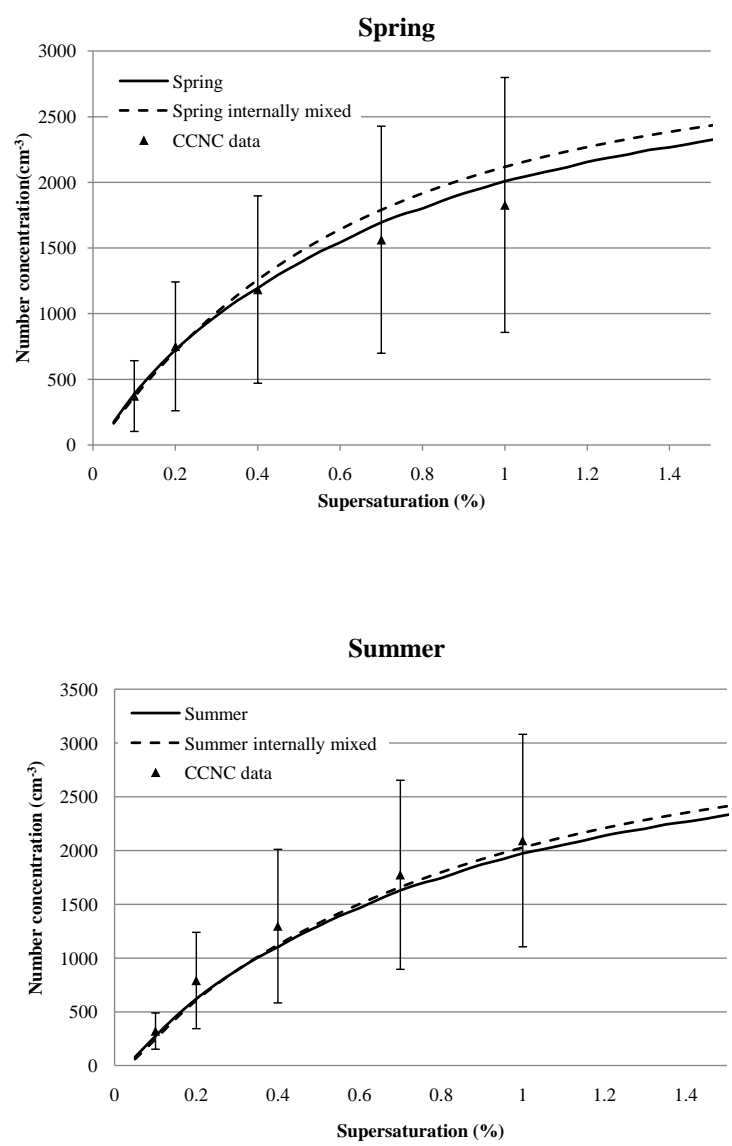

c)

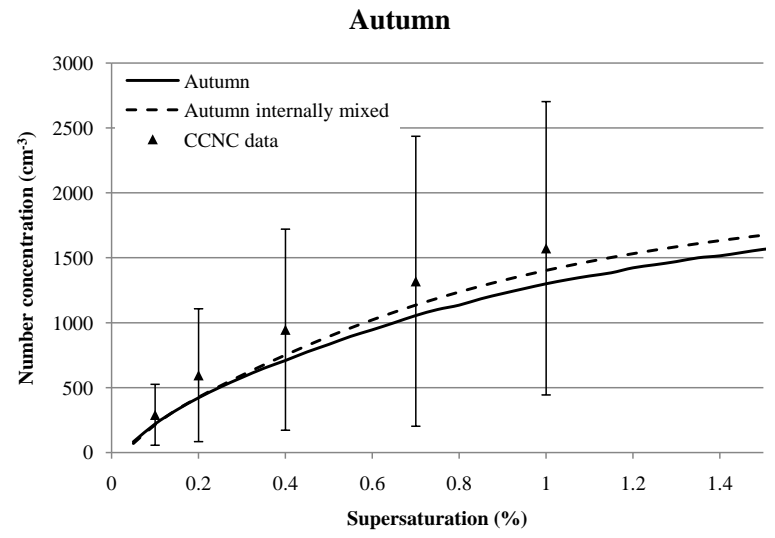

d)

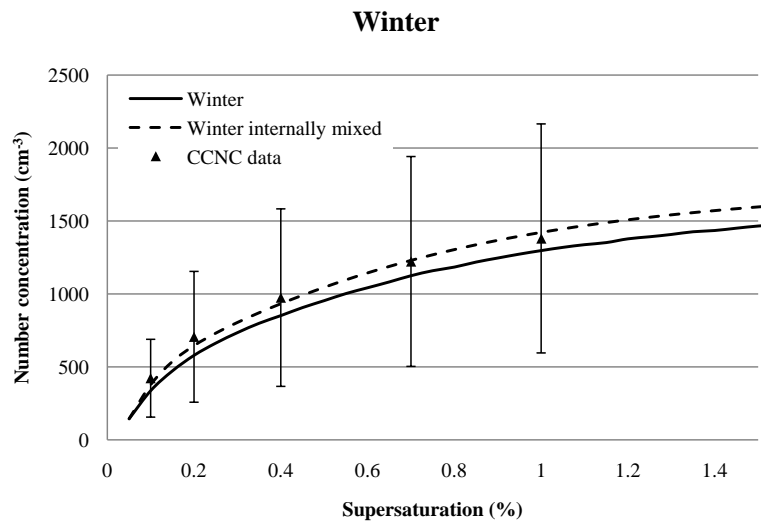

Fig. 10. Average measured $\mathrm{CCN}$ concentrations as a function of season and $s_{\mathrm{C}}$ denoted with symbols, and modeled values (internally and externally mixed) derived from averaged DMPS and H-TDMA data for the respective seasons. The error bars are standard deviations from the CCNC data.

processing, where soluble gases have added inorganic ions to the particle after the cloud drop dry out.

In general, the GFs of the modes in the averaged GF-PDFs were stable during the year, but the relative abundance of the modes changed with season. This seasonal cycle of the GF-PDFs was found to be most pronounced for the smallest particles. The mode of less hygroscopic particles increased in relative abundance during winter time. These less hygroscopic particles were more frequent during winter also for the larger particles, though the trend weakened with increasing size.
On a diurnal basis, all particles except $265 \mathrm{~nm}$ were found to have a higher growth factor during day-time than during night-time.

The CCN closure slightly underpredicted the number of activated $\mathrm{CCN}(s)$, from $\sim 30 \%$ at $0.2 \%$ sto $5 \%$ at $1 \% \mathrm{~s}$. The reason for this is unknown, though it is most likely connected to a combination of different measurement and modelling errors.

Finally it was concluded that seasonal averaged data from the DMPS and H-TDMA measurements well described the $\mathrm{CCN}$ concentrations from the DMT CCNC. It was also found 
Table 8. Properties of seasonal modal fits from averaged DMPS and H-TDMA data. $\mathrm{D}_{i}, \sigma_{i}$, and $\mathrm{N}_{i}$ are the geometric mean mode diameter, the width of the mode, and the number concentration in each mode respectively, where $i$ denotes mode number.

\begin{tabular}{lrrrr}
\hline & Spring & Summmer & Autumn & Winter \\
\hline $\mathrm{D}_{1}(\mathrm{~nm})$ & 7.9 & 12.4 & 10.2 & 9.5 \\
$\mathrm{D}_{2}(\mathrm{~nm})$ & 55.5 & 45.7 & 50.9 & 53.8 \\
$\mathrm{D}_{3}(\mathrm{~nm})$ & 187.5 & 135.2 & 186.3 & 177.3 \\
$\sigma_{1}$ & 2.02 & 2.02 & 2.02 & 2.02 \\
$\sigma_{2}$ & 2.02 & 1.82 & 1.85 & 1.68 \\
$\sigma_{3}$ & 1.99 & 1.68 & 1.60 & 1.68 \\
$\mathrm{~N}_{1}\left(\mathrm{~cm}^{-3}\right)$ & 795 & 1132 & 695 & 206 \\
$\mathrm{~N}_{2}\left(\mathrm{~cm}^{-3}\right)$ & 2478 & 2260 & 1743 & 1062 \\
$\mathrm{~N}_{3}\left(\mathrm{~cm}^{-3}\right)$ & 469 & 784 & 357 & 719 \\
$\mathrm{GF}_{1}$ & 1.33 & 1.31 & 1.30 & 1.29 \\
$\mathrm{GF}_{2}$ & 1.36 & 1.33 & 1.31 & 1.32 \\
$\mathrm{GF}_{3}$ & 1.52 & 1.44 & 1.46 & 1.49 \\
$\kappa_{1}$ & 0.22 & 0.21 & 0.20 & 0.19 \\
$\kappa_{2}$ & 0.22 & 0.20 & 0.18 & 0.19 \\
$\kappa_{3}$ & 0.30 & 0.25 & 0.25 & 0.28 \\
\hline
\end{tabular}

possible to simplify the aerosol description by assuming a bimodal size distribution with an average modal GF without significantly increasing the difference between measured and modelled CCN concentrations.

The results presented in this work may serve as input to models which desire to incorporate the hygroscopic properties of the atmospheric aerosol. However, the results also raise many unanswered questions regarding the mechanisms that control the hygroscopic properties of the ambient aerosol, and even though we have speculated around possible explanations for the different phenomena, deeper understanding of the processes involved will require detailed studies of the respective mechanisms.

Acknowledgements. This work was carried out with the support of the FP6 European Commission project European Supersites for Atmospheric Aerosol Research, EUSAAR, contract No. RII3CT-2006-026140, the European Integrated Project on Aerosol, Cloud, Climate and Air Quality Interactions, EUCAARI, contract number 036833-2, the Strategic Research Program MERGE: Modelling the Regional and Global Earth System, and Lund Centre for studies of Carbon Cycle and Climate Interaction LUCCI. The DMPS measurements at Vavihill were supported by the Swedish Environmental Protection Agency within the Swedish Environmental Monitoring Program. The support by the Swedish Research Council for Environment, Agricultural Sciences and Spatial Planning (Formas) through project no 2009-615 and 2008-1467 is also gratefully acknowledged. Finally Joonas Merikanto is acknowleded for valuable discussions on how to best incorporate hygroscopic data in global models and Martin Gysel is acknowledged for the use of the TDMA inversion algorithm TDMAinv.
Edited by: V.-M. Kerminen

\section{References}

Boy, M., Petäjä, T., Dal Maso, M., Rannik, Ü., Rinne, J., Aalto, P., Laaksonen, A., Vaattovaara, P., Joutsensaari, J., Hoffmann, T., Warnke, J., Apostolaki, M., Stephanou, E. G., Tsapakis, M., Kouvarakis, A., Pio, C., Carvalho, A., Römpp, A., Moortgat, G., Spirig, C., Guenther, A., Greenberg, J., Ciccioli, P., and Kulmala, M.: Overview of the field measurement campaign in Hyytil, August 2001 in the framework of the EU project OSOA, Atmos. Chem. Phys., 4, 657-678, doi:10.5194/acp-4-657-2004, 2004.

Draxler, R. and Hess, G.: Description of the HYSPLIT_4 modeling system, NOAA Technical Memorandum ERL ARL-224, 24, 1997.

Duplissy, J., Gysel, M., Sjogren, S., Meyer, N., Good, N., Kammermann, L., Michaud, V., Weigel, R., Martins dos Santos, S., Gruening, C., Villani, P., Laj, P., Sellegri, K., Metzger, A., McFiggans, G. B., Wehrle, G., Richter, R., Dommen, J., Ristovski, Z., Baltensperger, U., and Weingartner, E.: Intercomparison study of six HTDMAs: results and recommendations, Atmos. Meas. Tech., 2, 363-378, doi:10.5194/amt-2-363-2009, 2009.

Dusek, U., Frank, G., Hildebrandt, L., Curtius, J., Schneider, J., Walter, S., Chand, D., Drewnick, F., Hings, S., Jung, D., Borrman, S., and Andreae, M. O.: Size matters more than chemistry for cloud-nucleating ability of aerosol particles, Science, 312, 1375-1378, 2006.

Ehn, M., Petj, T., Aufmhoff, H., Aalto, P., Hmeri, K., Arnold, F., Laaksonen, A., and Kulmala, M.: Hygroscopic properties of ultrafine aerosol particles in the boreal forest: diurnal variation, solubility and the influence of sulfuric acid, Atmos. Chem. Phys., 7, 211-222, doi:10.5194/acp-7-211-2007, 2007.

Fierz-Schmidhauser, R., Zieger, P., Wehrle, G., Jefferson, A., Ogren, J. A., Baltensperger, U., and Weingartner, E.: Measurement of relative humidity dependent light scattering of aerosols, Atmos. Meas. Tech., 3, 39-50, doi:10.5194/amt-3-392010, 2010.

Genberg, J., Hyder, M., Stenström, K., Bergström, R., Simpson, D., Fors, E., Jönsson, J. Å., and Swietlicki, E.: Source apportionment of carbonaceous aerosol in southern Sweden, Atmos. Chem. Phys. Discuss., 11, 13575-13616, doi:10.5194/acpd-1113575-2011, 2011.

Graber, E. R. and Rudich, Y.: Atmospheric HULIS: How humiclike are they? A comprehensive and critical review, Atmos. Chem. Phys., 6, 729-753, doi:10.5194/acp-6-729-2006, 2006.

Gysel, M., McFiggans, G., and Coe, H.: Inversion of tandem differential mobility analyser (TDMA) measurements, J. Aerosol Sci., 40, 134-151, 2009.

Hussein, T., Dal Maso, M., Petäjä, T., Koponen, I. K., Paatero, P., Aalto, P. P., Hameri, K., and Kulmala, M.: Evaluation of an automatic algorithm for fitting the particle number size distributions, Boreal Env. Res., 10, 337-355, 2005.

Hämeri, K., Väkevä, M., Aalto, P., Kulmala, M., Swietlicki, E., Zhou, J., Seidl, W., Becker, E., and O'dowd, C.: Hygroscopic and $\mathrm{CCN}$ properties of aerosol particles in boreal forests, Tellus B, 53, 359-379, 2001.

Jimenez, J. L., Canagaratna, M. R., Donahue, N. M., Prevot, A. S. H., Zhang, Q., Kroll, J. H., DeCarlo, P. F., Allan, J. D., Coe, H., 
Ng, N., Aiken, A. C., Docherty, K. S., Ulbrich, I. M., Grieshop, A. P., Robinson, A. L., Duplissy, J., Smith, J. D., Wilson, K. R., Lanz, V. A., Hueglin, C., Sun, Y. L., Tian, J., Laaksonen, A., Raatikainen, T., Rautiainen, J., Vaattovaara, P., Ehn, M., Kulmala, M., Tomlinson, J. M., Collins, D. R., Cubison, M. J., Dunlea, J., Huffman, J. A., Onasch, T. B., Alfarra, M. R., Williams, P. I., Bower, K., Kondo Y., Schneider, J., Drewnick, F., Borrmann, S., Weimer, S., Demerjian, K., Salcedo, D., Cottrell, L., Griffin, R., Takami, A., Miyoshi, T., Hatakeyama, S., Shimono, A., Sun, J. Y., Zhang, Y. M., Dzepina, K., Kimmel, J. R., Sueper, D., Jayne, J. T., Herndon, S. C., Trimborn, A. M., Williams, L. R., Wood, E. C., Middlebrook, A. M., Kolb, C. E., Baltensperger, U., and Worsnop, D. R.: Evolution of organic aerosols in the atmosphere, Science, 326, 1525-1529, 2009.

Kammermann, L., Gysel, M., Weingartner, E., and Baltensperger, U.: 13-month climatology of the aerosol hygroscopicity at the free tropospheric site Jungfraujoch (3580 ma.s.1.), Atmos. Chem. Phys., 10, 10717-10732, doi:10.5194/acp-10-107172010, 2010a.

Kammermann, L., Gysel, M., Weingartner, E., Herich, H., Cziczo, D. J., Holst, T., Svenningsson, B., Arneth, A., and Baltensperger, U.: Subarctic atmospheric aerosol composition: 3. Measured and modeled properties of cloud condensation nuclei, J. Geophys. Res., 115, D04202, doi:10.1029/2009jd012447, 2010b.

Kristensson, A., Dal Maso, M., Swietlicki, E., Hussein, T., Zhou, J., Kerminen, V. M., and Kulmala, M.: Characterization of new particle formation events at a background site in Southern Sweden: relation to air mass history, Tellus B, 60, 330-344, 2008.

Lanz, V. A., Alfarra, M. R., Baltensperger, U., Buchmann, B., Hueglin, C., and Prévôt, A. S. H.: Source apportionment of submicron organic aerosols at an urban site by factor analytical modelling of aerosol mass spectra, Atmos. Chem. Phys., 7, 1503-1522, doi:10.5194/acp-7-1503-2007, 2007.

Massling, A., Stock, M., and Wiedensohler, A.: Diurnal, weekly, and seasonal variation of hygroscopic properties of submicrometer urban aerosol particles, Atmos. Env., 39, 3911-3922, 2005.

McFiggans, G., Artaxo, P., Baltensperger, U., Coe, H., Facchini, M. C., Feingold, G., Fuzzi, S., Gysel, M., Laaksonen, A., Lohmann, U., Mentel, T. F., Murphy, D. M., O’Dowd, C. D., Snider, J. R., and Weingartner, E.: The effect of physical and chemical aerosol properties on warm cloud droplet activation, Atmos. Chem. Phys., 6, 2593-2649, doi:10.5194/acp-6-2593-2006, 2006.

Nilsson, E., Swietlicki, E., Sjogren, S., Lndahl, J., Nyman, M., and Svenningsson, B.: Development of an H-TDMA for longterm unattended measurement of the hygroscopic properties of atmospheric aerosol particles, Atmos. Meas. Tech., 2, 313-318, doi:10.5194/amt-2-313-2009, 2009.

Petäjä, T., Kerminen, V.-M., Hämeri, K., Vaattovaara, P., Joutsensaari, J., Junkermann, W., Laaksonen, A., and Kulmala, M.: Effects of $\mathrm{SO}_{2}$ oxidation on ambient aerosol growth in water and ethanol vapours, Atmos. Chem. Phys., 5, 767-779, doi:10.5194/acp-5-767-2005, 2005.

Petters, M. and Kreidenweis, S.: A single parameter representation of hygroscopic growth and cloud condensation nucleus activity, Atmos. Chem. Phys., 7, 1961-1971, 2007, http://www.atmos-chem-phys.net/7/1961/2007/.

Potukuchi, S. and Wexler, A. S.: Identifying solid-aqueous phase transitions in atmospheric aerosols-I., Neutral-acidity solutions,
Atmos. Env., 29, 1663-1676, 1995.

Raatikainen, T., Vaattovaara, P., Tiitta, P., Miettinen, P., Rautiainen, J., Ehn, M., Kulmala, M., Laaksonen, A., and Worsnop, D. R.: Physicochemical properties and origin of organic groups detected in boreal forest using an aerosol mass spectrometer, Atmos. Chem. Phys., 10, 2063-2077, doi:10.5194/acp-10-20632010, 2010.

Rader, D. and McMurry, P.: Application of the tandem differential mobility analyzer to studies of droplet growth or evaporation, J. Aerosol Sci., 17, 771-787, 1986.

Rissler, J., Swietlicki, E., Zhou, J., Roberts, G., Andreae, M. O., Gatti, L. V., and Artaxo, P.: Physical properties of the submicrometer aerosol over the Amazon rain forest during the wetto-dry season transition - comparison of modeled and measured CCN concentrations, Atmos. Chem. Phys., 4, 2119-2143, doi:10.5194/acp-4-2119-2004, 2004.

Rissler, J., Vestin, A., Swietlicki, E., Fisch, G., Zhou, J., Artaxo, P., and Andreae, M. O.: Size distribution and hygroscopic properties of aerosol particles from dry-season biomass burning in Amazonia, Atmos. Chem. Phys., 6, 471-491, doi:10.5194/acp6-471-2006, 2006.

Rissler, J., Svenningsson, B., Fors, E. O., Bilde, M., and Swietlicki, E.: An evaluation and comparison of cloud condensation nucleus activity models: Predicting particle critical saturation from growth at subsaturation, J. Geophys. Res., 115, D22208, doi:10.1029/2010JD014391, 2010.

Rose, D., Frank, G. P., Dusek, U., Gunthe, S. S., Andreae, M. O., and Pöschl, U.: Calibration and measurement uncertainties of a continuous-flow cloud condensation nuclei counter (DMTCCNC): CCN activation of ammonium sulfate and sodium chloride aerosol particles in theory and experiment, Atmos. Chem. Phys. Discuss., 7, 8193-8260, doi:10.5194/acpd-7-8193-2007, 2007.

Rosenfeld, D.: TRMM observed first direct evidence of smoke from forest fires inhibiting rainfall, Geophys. Res. Lett., 26, 31053108, 1999.

Rosenfeld, D.: Suppression of rain and snow by urban and industrial air pollution, Science, 287, 1793-1796, 2000.

Seinfeld, J. H. and Pandis, S. N.: Atmospheric chemistry and physics: from air pollution to climate change, 2nd edn., Wiley Intersci., New York, USA, 2006.

Sekigawa, K.: Estimation of the volume fraction of water soluble material in submicron aerosols in the atmosphere, J. Meteorol. Soc. Japan, 61, 359-367, 1983.

Simoneit, B. R. T., Schauer, J. J., Nolte, C., Oros, D. R., Elias, V. O., Fraser, M., Rogge, W., and Cass, G. R.: Levoglucosan, a tracer for cellulose in biomass burning and atmospheric particles, Atmos. Environ., 33, 173-182, 1999.

Solomon, S., Qin, D., Manning, M., Chen, Z., Marquis, M., Averyt, K. B., Tignor, M., and Miller, H. L.: Climate change 2007: the physical science basis, Cambridge University Press, Cambridge, UK, 2007.

Swietlicki, E., Hansson, H. C., Hämeri, K., Svenningsson, B., Massling, A., McFiggans, G., McMurry, P., Petäjä, T., Tunved, P., Gysel, M., Topping, D., Weingartner, E., Baltensperger, U., Rissler, J., Wiedensohler, A., and Kulmala, M.: Hygroscopic properties of submicrometer atmospheric aerosol particles measured with H TDMA instruments in various environments - A review, Tellus B, 60, 432-469, 2008. 
Tang, I. N. and Munkelwitz, H. R.: Water activities, densities and refractive-indexes of aqueous sulfates and sodium-nitrate droplets of atmospheric importance, J. Geophys. Res., 99(D9), 18801-18808, 1994.

Twomey, S.: The nuclei of natural cloud formation part II: The supersaturation in natural clouds and the variation of cloud droplet concentration, Pure Appl. Geophys., 43, 243-249, 1959.

Warner, J.: The supersaturation in natural clouds, J. Rech. Atmos., 3, 233-237, 1968.

Wiedensohler, A., Birmili, W., Nowak, A., Sonntag, A., Weinhold, K., Merkel, M., Wehner, B., Tuch, T., Pfeifer, S., Fiebig, M., Fjäraa, A. M., Asmi, E., Sellegri, K., Depuy, R., Venzac, H., Villani, P., Laj, P., Aalto, P., Ogren, J. A., Swietlicki, E., Roldin,
P., Williams, P., Quincey, P., Hüglin, C., Fierz-Schmidhauser, R., Gysel, M., Weingartner, E., Riccobono, F., Santos, S., Grüning, C., Faloon, K., Beddows, D., Harrison, R. M., Monahan, C., Jennings, S. G., O’Dowd, C. D., Marinoni, A., Horn, H.-G., Keck, L., Jiang, J., Scheckman, J., McMurry, P. H., Deng, Z., Zhao, C. S., Moerman, M., Henzing, B., and de Leeuw, G.: Particlemobility size spectrometers: harmonization of technical standards and data structure to facilitate high quality long-term observations of atmospheric particle number size distributions, Atmos. Meas. Tech. Discuss., 3, 5521-5587, doi:10.5194/amtd3-5521-2010, 2010. 